\title{
Lessons from the Case History of a Massive Landslide Dam
}

\author{
Fawad S. Niazi $\mathbb{D}^{1},{ }^{1}$ Aranzazu Pinan-Llamas $\mathbb{D}^{2},{ }^{2}$ and Kamran Akhtar $\mathbb{D}^{3}$ \\ ${ }^{1}$ Department of Civil \& Mechanical Engineering, Purdue University Fort Wayne, Indiana 46805, USA \\ ${ }^{2}$ School of Polytechnic, Purdue University Fort Wayne, Indiana 46805, USA \\ ${ }^{3}$ National University of Sciences and Technology, Balochistan Campus, Quetta, Pakistan \\ Correspondence should be addressed to Fawad S. Niazi; niazif@pfw.edu
}

Received 5 August 2020; Revised 10 September 2020; Accepted 4 October 2020; Published 30 November 2020

Academic Editor: Ching Hung

Copyright $\odot 2020$ Fawad S. Niazi et al. This is an open access article distributed under the Creative Commons Attribution License, which permits unrestricted use, distribution, and reproduction in any medium, provided the original work is properly cited.

\begin{abstract}
A massive landslide created a natural dam on two tributaries of Jhelum River near the town of Hattian Bala in Kashmir in October 2005. The landslide was triggered by a $7.6 \mathrm{M}_{\mathrm{w}}$ earthquake. The resulting unconsolidated dam and water impoundment upstream carried hazard potential of downstream damage to both infrastructure and population due to potential flooding caused by its breach. Comprehensive investigations and monitoring were implemented to analyse dam stability. Fresh topographic profiles were generated. Samples of the matrix materials were utilized in the laboratory investigations including grain-size analysis, laboratory electrical resistivity and permeability tests at varying densities and degrees of saturation, and sediment concentration assessment in the seepage discharge. A noninvasive geophysical method was employed together with new topographic information to develop transient subsurface pictures and to assess the advancement of seepage fronts within the dam body. Internal erosion/filtering potential of the matrix material was assessed by comparing grain size distributions with those of the earlier failed dams. Upstream inflows, downstream discharges, daily precipitation, and lake levels monitored during the study period were utilized in hydrological data analysis in an attempt to assess the potential seepage volume. A combination of empirical, analytical, and numerical methods and simulations, together with laboratory and field investigations, led to the interpretations regarding short- and long-term stability of the dam. This paper highlights alternative methods of investigation employed differently from those used by other national and international agencies in analysing the failure potential of this natural dam. It offers lessons learned from a case history that can be beneficial in future evaluation of seepage-induced failure of similar natural features.
\end{abstract}

\section{Introduction}

Landslide dams are both common and complicated natural features. They are regarded as transient events on geomorphologic timescale. Their significance lies in the temporal disruption of water channels due to accumulation of debris at the interface between unstable hill slopes and valley floors, resulting in stream impoundments. These impoundments pose vulnerability to the downstream population and infrastructure due to the possibility of catastrophic damage, which can be caused by the dam outburst. Costa and Schuster [1] have shown that most landslide dam failures occur within the first year of their formation and that the outburst floods become more unlikely as they stay longer. However, impact waves triggered by mass movements into the lake and cloud bursts/heavy rains are also known to have caused failure a very long time after the formation of the dam. According to Schuster [2], 55\% of 187 investigated examples worldwide failed within one week of their formation, whereas $89 \%$ failed within one year.

Failure of landslide dams is known to occur due to overtopping or slope instability or seepage-induced erosion or a combination of these causes. Seepage-induced piping/internal erosion and high confined pore pressures in the body of the landslide dams have been reported as the most probable failure phenomena $[3,4]$. Nonetheless, advance prediction of the likely failure mechanism of each dam and assessment of its transient state of stability are constrained by the peculiarities of local geology, topography, geotechnical properties of the dam body, and streamflow/seepage patterns. Owing to their rapid creation, ephemeral nature, and the inhomogeneous properties of the geomaterials within the dam body, 


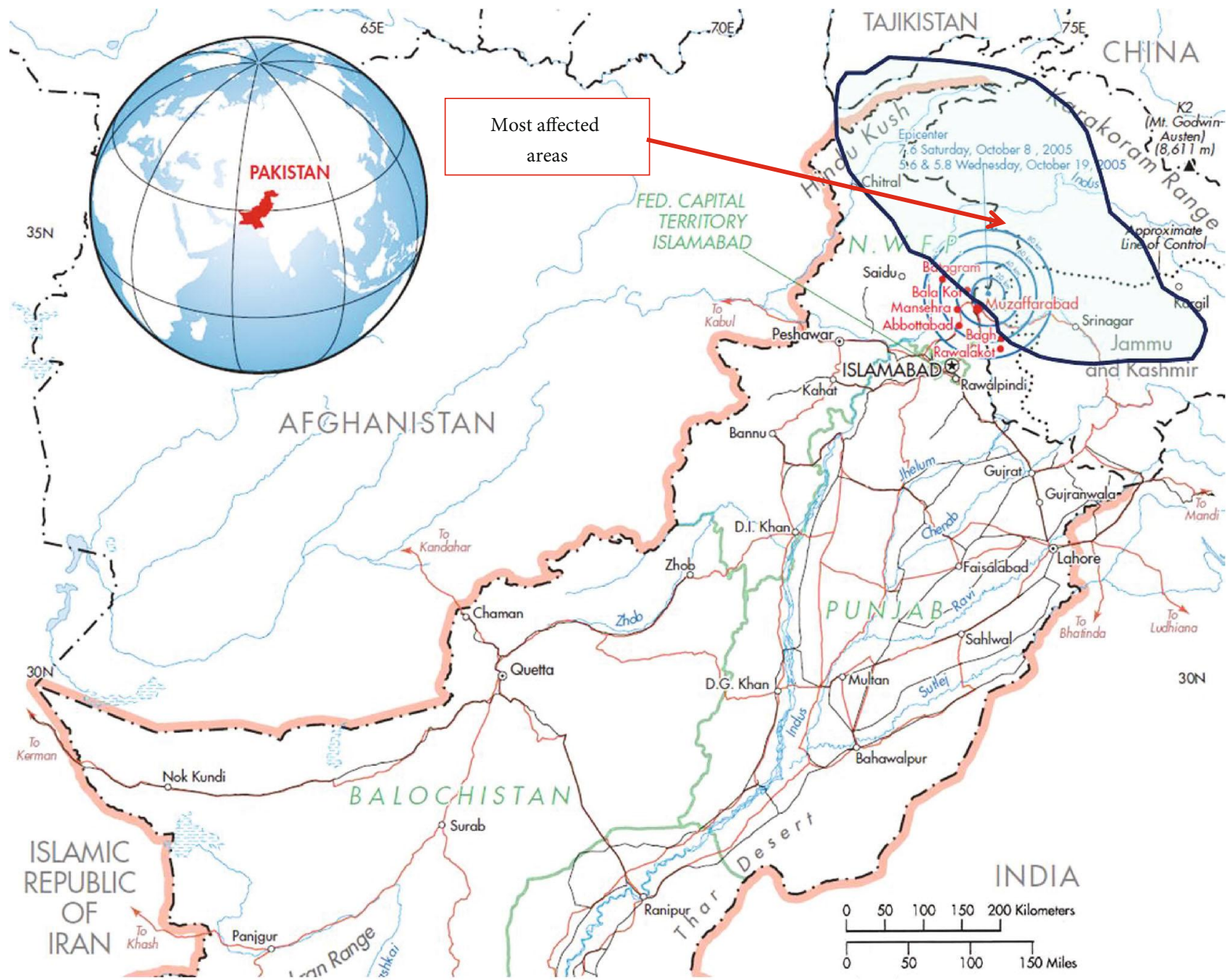

FIgure 1: Map showing the epicenter of the October 08, 2005, earthquake and the most affected area (adapted from [6]).

a certain degree of lack of understanding of the forms and processes involved still remains. Despite a host of documented case studies, the multivariate geomorphic characteristics inherent in landslide dams continue to pose problems for defining an exact basis of comparison. Yet, it is of high significance to derive, from each case study, a set of key characteristics and indicators. These efforts are likely to assist in continuous improvement of our understanding towards hazard appraisal in future events and for planning of monitoring mechanisms, early warning systems, and mitigation strategies to limit the potential of disasters. This paper has been developed under such motivation.

On October 08, 2005, at 8:50 AM Pakistan Standard Time, a $7.6 \mathrm{M}_{\mathrm{w}}$ earthquake [5] struck in northern Pakistan, Afghanistan, and Kashmir. The earthquake epicenter was located near Muzaffarabad, about $100 \mathrm{~km}$ north-northeast of Pakistan's capital city of Islamabad, along a fault associated with the Indian microplate moving northward and indenting at a rate of about $40 \mathrm{~mm} / \mathrm{yr}$ in the Eurasian plate [6]. Pakistan-administered Kashmir, known as Azad Jammu and Kashmir (AJK), and the eastern districts of Pakistan's
Khyber Pakhtunkhwa Province (previously known as N.W.F.P.) bore the full force of the earthquake (see Figure 1). Since the affected region was predominantly mountainous, it was badly struck by slope failures in the form of small to large landslides.

The most significant single landslide triggered due to this catastrophic event that caught the world's attention was the one located $3.5 \mathrm{~km}$ upstream of the confluence of the Jhelum river and Karli water channel near the town of Hattian Bala, AJK [5] (see Figure 2(a)). This landslide originated on Dana Hill (2080 $\mathrm{m}$ above sea level (AMSL), $34^{\circ} 09^{\prime} \mathrm{N} / 73^{\circ} 43^{\prime} \mathrm{E}$ ) [1] and carried a debris volume of around 85 million $\mathrm{m}^{3}$, which blocked two tributaries of Jhelum River, namely, Karli (a.k.a. Zalzal) and Tung (a.k.a. Salmeah) water channels at their confluence (see Figure 2(b)). This blockage resulted in impoundment of water and creation of lakes on the upstream sides of the debris material (hereinafter referred to as a landslide dam). These lakes turned into a potential hazard for the downstream population and infrastructure, principally in the case of the Karli channel because of its higher inflow rate, significantly large impoundment capacity (i.e., $>60$ million $\mathrm{m}^{3}$ 


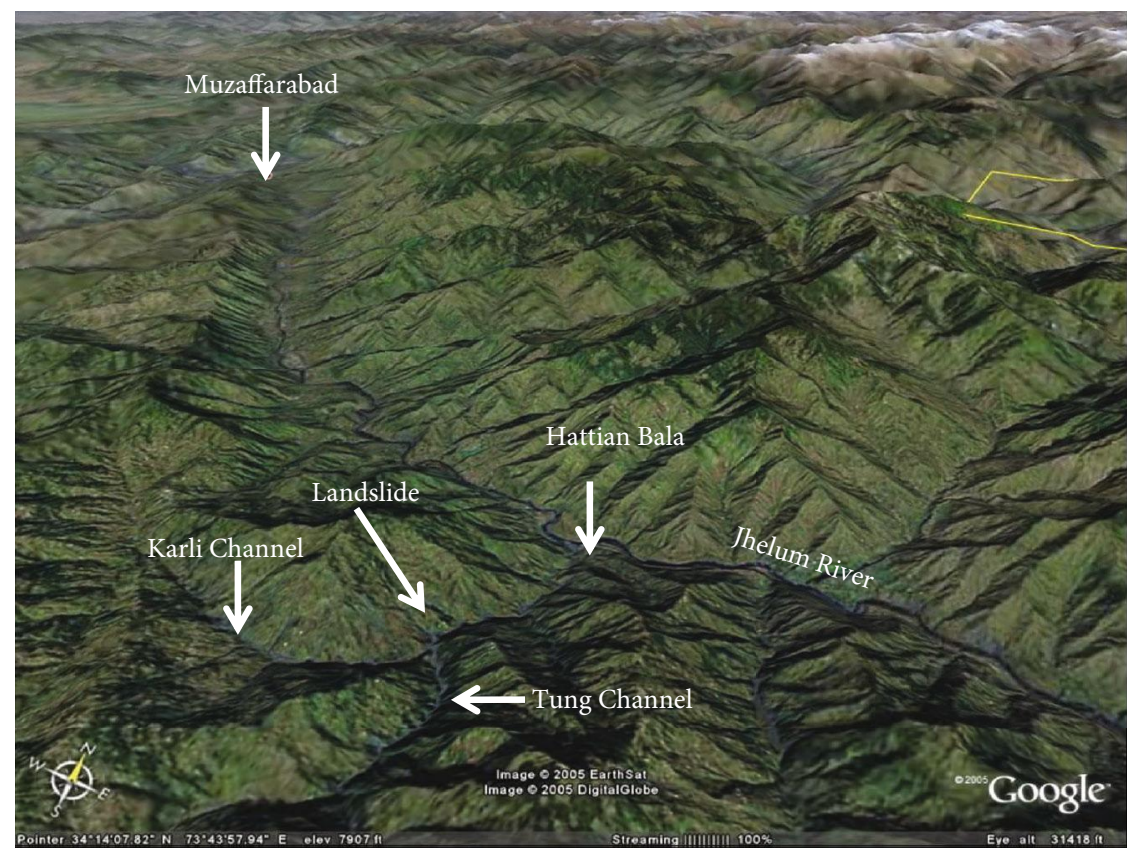

(a)

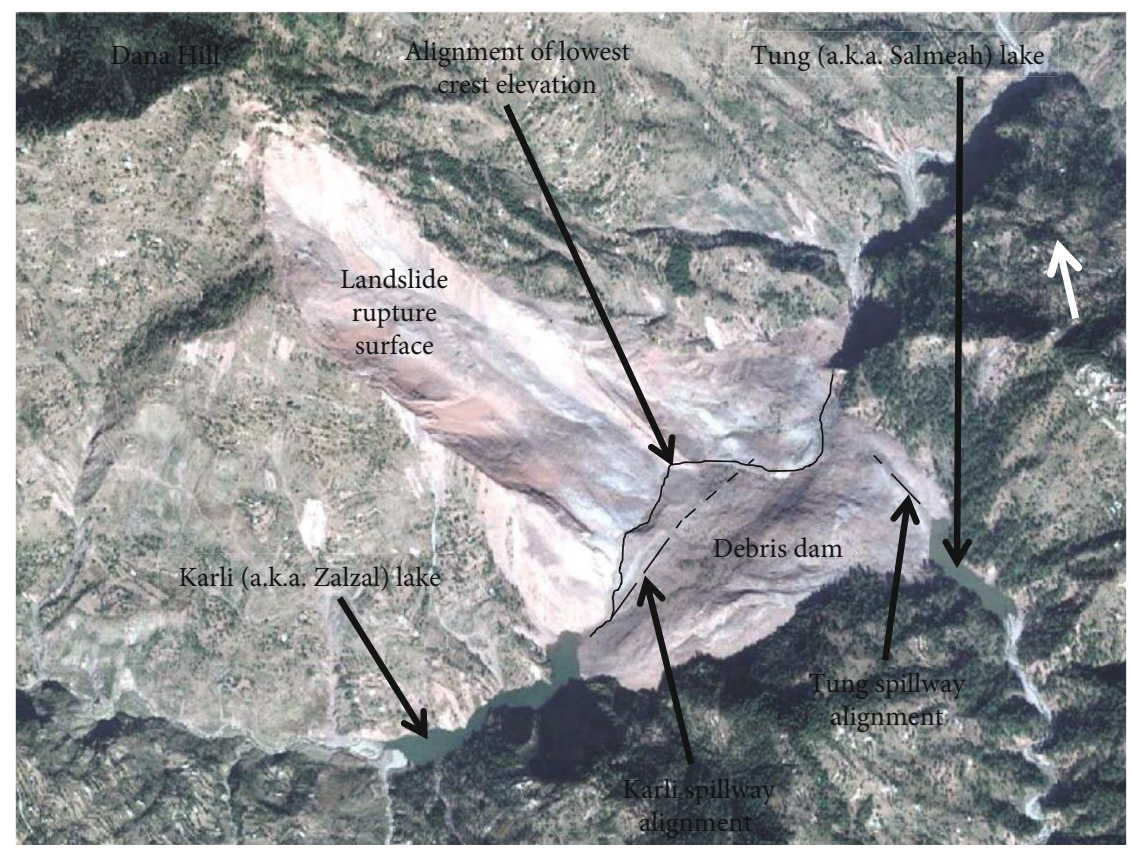

(b)

Figure 2: (a) 3D view of Hattian Bala landslide and surrounding area [7]; (b) satellite imagery of Hattian Bala landslide, dam, and lakes [5].

of water), and the major portion of the landslide dam blocking its flow. Figure 3 shows different pictorial views of the landslide dam area for comprehension of the orientation and scale of the problem. Certain details marked on these pictures (e.g., spillways) are discussed in later parts of this paper.

\section{Preliminary Investigations and Initial Recommendations}

To analyse the situation, a number of studies were undertaken and monitoring systems were set by various national and international agencies. Of notable mention are those by the Norwegian Geotechnical Institute (NGI), Pakistan Army Engineer-in-Chief's Task Force consisting of Frontier Works Organization (FWO), Geological Survey of Pakistan (GSP), Water and Power Development Authority (WAPDA), Army Survey Group Engineers (ASGE), and National Engineering Services Pakistan (NESPAK) Limited. It is important to note that the fundamental purpose of these studies was the estimation of threat potential and the enforcement of monitoring, and appropriate mitigation measures before the transitory stability of the dam were overcome by the driving forces. 


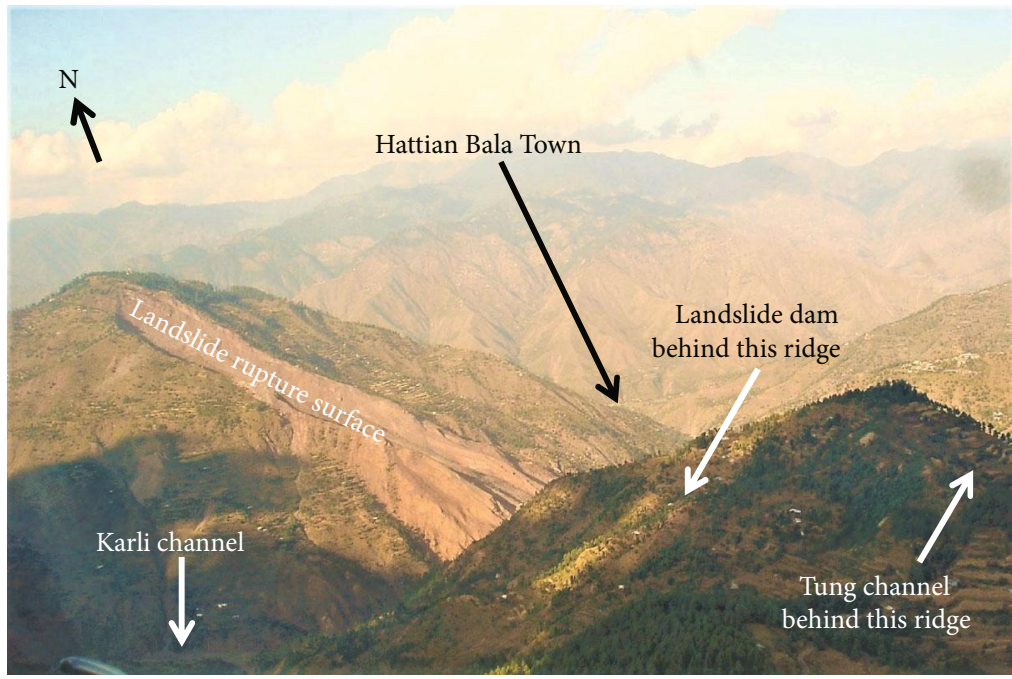

(a)

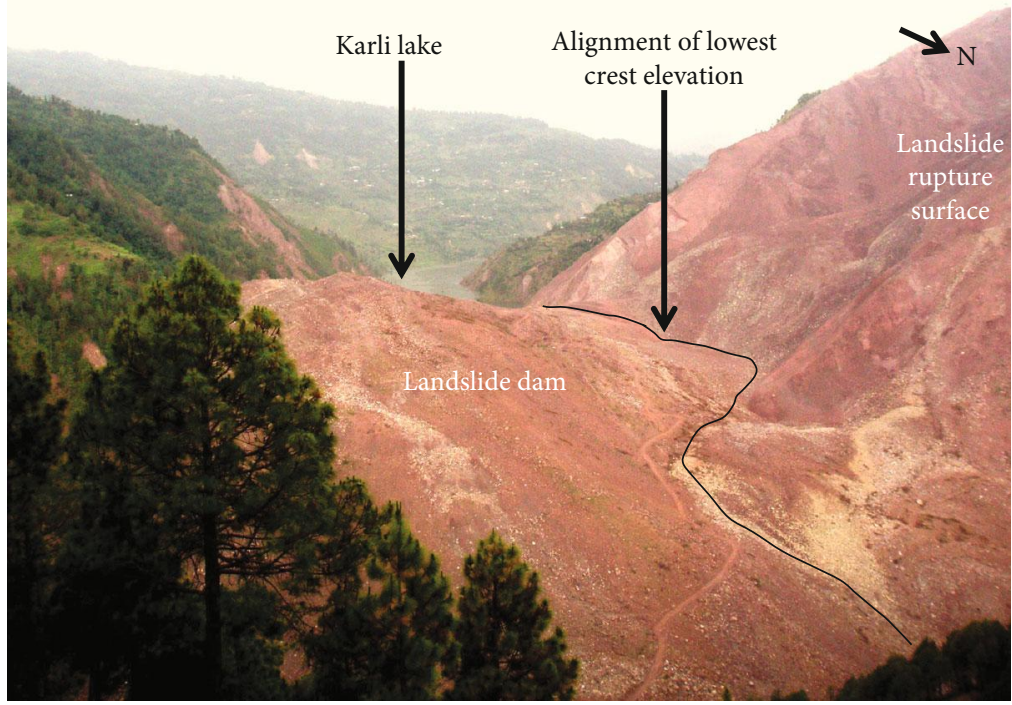

(b)

Figure 3: Continued. 


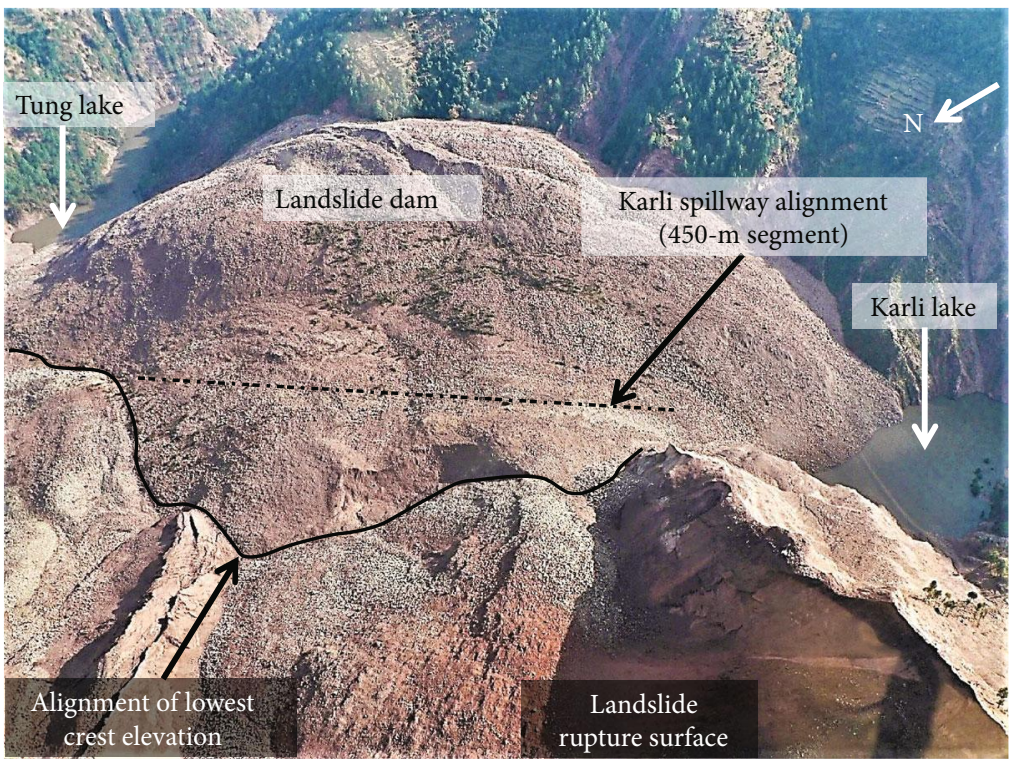

(c)

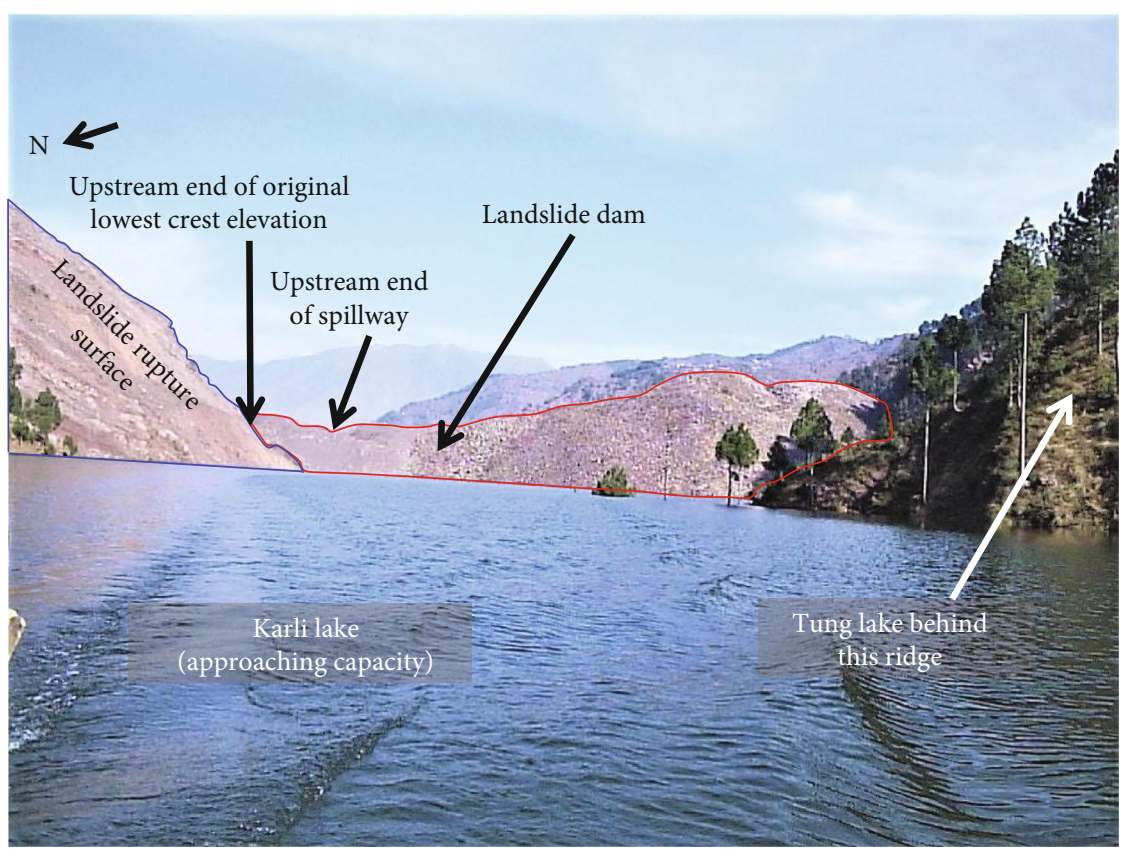

(d)

FIgURE 3: Pictures showing (a) landslide rupture surface and Karli water channel, taken from the upstream side of the dam facing eastward (November 2005); (b) landslide rupture surface, dam, Karli lake, and alignment of the original lowest crest elevation along the dam, taken from the downstream side of the dam facing westward (April 2006); (c) landslide rupture surface, landslide toe, dam, Karli and Tung lakes, and alignments of the original lowest crest elevation and the Karli spillway along the dam surface, taken from the top of the landslide (November 2005); (d) landslide rupture surface, dam, Karli lake, and upstream ends of the original lowest crest elevation and the Karli spillway, taken from Karli lake (December 2006).

2.1. Investigations and Data Collection. The following is a list of data collected and investigations performed by these agencies:

(i) $2 \mathrm{D}$ and $3 \mathrm{D}$ satellite imageries of the area

(ii) $1: 50,000$ scale topographic map and 1:10,000 scale geological map of the area (iii) Fresh topographic survey and $2 \mathrm{~m}$ interval contour map of the landslide dam and the potential lake area

(iv) Hydrological and landslide inventory maps of the area

(v) Seismic refraction tests along five $110 \mathrm{~m}$ and one $230 \mathrm{~m}$ long survey lines at selected locations on the dam surface 
(vi) Laboratory testing on rock and soil samples collected from the dam surface, including water content $(w)$, specific gravity $\left(G_{\mathrm{s}}\right)$, uniaxial compression, and index properties

(vii) Hydrological data including lakes' elevationcapacity relationships, average/wet year flows of the two water channels, and average monthly rainfall

(viii) Seepage discharge assessment for increasing lake levels, assuming homogeneous composition of the dam and for a range of permeability $(k)$ values for the dam body and the bed materials

(ix) Slope stability analysis for increasing lake levels, assuming homogeneous dam composition of the dam with a range of cohesion and friction $(c-\phi)$ parameters

2.2. Findings. The aggregated salient findings from these studies are summarily presented below $[1,8,9]$ :

(i) The Hattian Bala landslide dam was located in a geological zone characterized by the presence of the Early-Middle Miocene Murree and Kamlial Formations (Cenozoic era). These formations include dark red to purple and greenish gray sandstone, purple to reddish brown mudstone (shale), and lenses of conglomerate [1]

(ii) The dam consisted of rock fragments floating in a fine matrix of medium and fine sand with silt and clay-sized particles

(iii) A portion of the dam blocking the Karli channel was composed of cobble-, boulder-, and gravelsized geomaterials embedded in a dominant matrix of fines, whereas that obstructing the Tung channel was formed mainly by cobble- and boulder-sized debris, with a limited ratio of gravels and finer particles

(iv) The landslide dam body could be divided into two layers with the top layer having smaller proportions of less compacted fine material and the lower layer of comparatively larger proportion of highly compacted fines

(v) The rise in the water level in Karli lake was not commensurate with its recorded total inflow over the study period, indicating significant infiltration into the dam body

(vi) At the average monthly rainfall rate, the dam portion blocking Tung channel would overtop in March 2006, while it could happen earlier with an above-average rate

(vii) The portion of the dam blocking Karli lake would overtop along its lowest crest elevation (adjacent to the toe of the landslide (see Figures 2(b), 3(b), and 3(c))) in March 2011 under average monthly rainfall, and in June 2006 at around the upper limit of 90 percentile rate of rainfall

(viii) The highest point along this lowest crest elevation was $1368 \mathrm{~m}$ AMSL, which would become the surface elevation of Karli lake when filled to its maximum capacity

(ix) Failure of the dam could occur due to internal erosion/piping caused by seepage or retrogressive surface erosion due to overtopping flow starting at the downstream toe

(x) With an assumed $k$ of the dam material $\geq 1 \times 10^{-5}$ $\mathrm{m} / \mathrm{s}$, and that of the original stream bed as $1 \times$ $10^{-8} \mathrm{~m} / \mathrm{s}$, it would take a minimum of 4 months after the overtopping of Karli lake to develop a steady-state seepage flow through the dam body. Seepage near the downstream toe would develop after that period. This duration would increase if the actual $k$ was lower than these assumptions

(xi) After the filling of Karli lake to its capacity and the development of a steady-state seepage flow, the downstream slope of the dam would become unstable for an assumed effective friction angle $\left(\phi^{\prime}\right)$ of $<30^{\circ}$ with cohesion intercept of zero for the dam material. It would be stable for $\phi^{\prime}$ values $\geq 30^{\circ}$ under static loading. The upstream slope was estimated to be stable for these assumed values

2.3. Recommendations. The following main recommendations were made to mitigate the hazard potential based on the above findings $[1,8,9]$ :

(i) Construction of spillways through the dam in front of both lakes with their sizes and dimensions appropriate to handle extreme discharge events

(ii) Prioritized immediate construction of the Tung spillway to eliminate that part of the overall hazard, followed by the Karli spillway

(iii) Lining the bed and sides of the Karli spillway with boulder- to cobble-sized particles to prevent uncontrolled erosion

(iv) Avoidance of overtopping flow from Karli lake to follow the path along the lowest crest elevation, which could have made the slope along the toe of the landslide rupture surface unstable and result in another catastrophe

(v) Construction of the lined Karli spillway as far eastward of the landslide toe as feasible and dumping of the excavated material along the landslide toe (i.e., into and along the original lowest crest elevation) to enhance its stability

(vi) Implementation of recommended measures prior to the filling of Karli lake to its maximum capacity, preferably before the next monsoon season of year 2006 


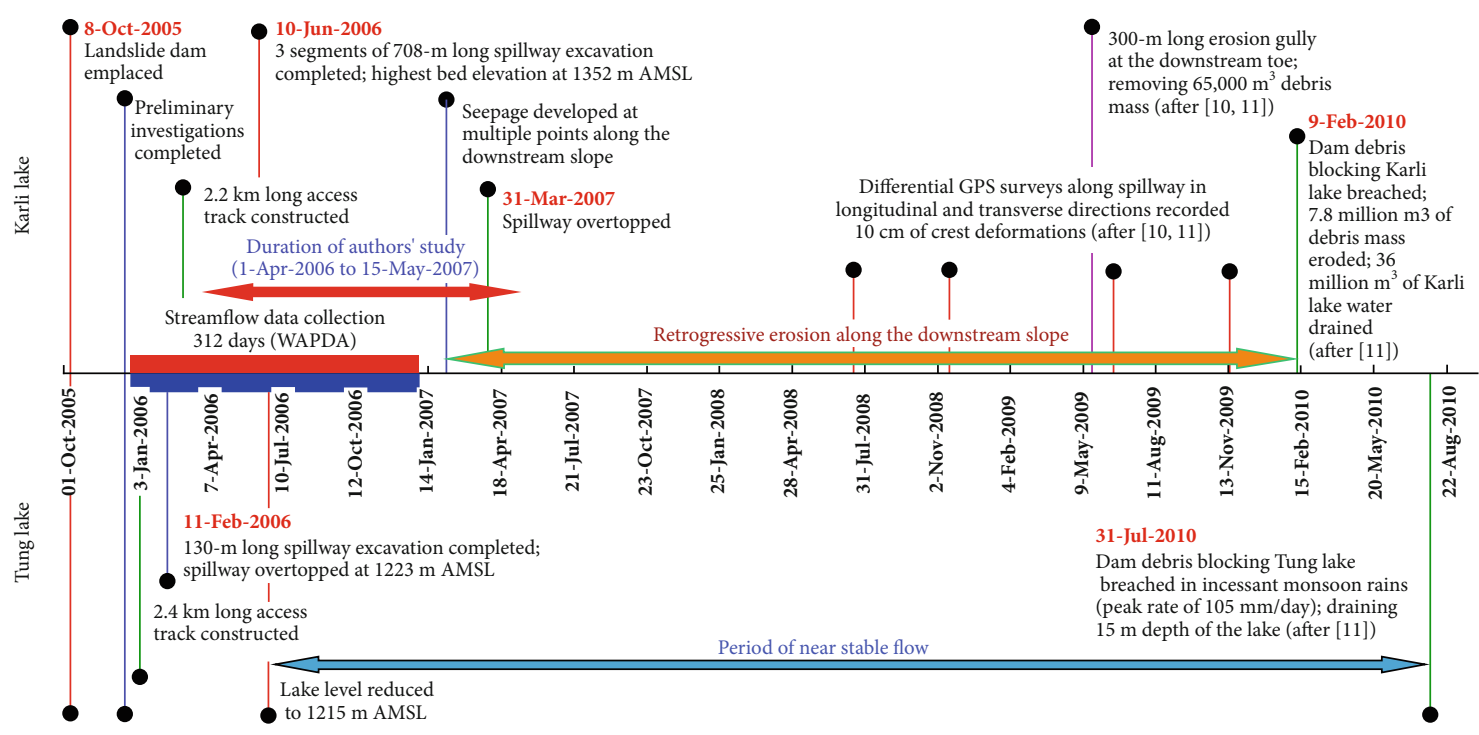

Figure 4: Chronology of events that occurred at the Hattian Bala landslide dam site from its creation to its breach (October 8, 2005, to July 31 , 2010).

\section{Implementation of Mitigation and Monitoring Measures and Chronology of Events}

Due to the urgency against the danger of dam breach, recommendations from the investigations and studies summarized above were made to the authorities at the end of December 2005, although formal reports were finalized in a later time frame. The mitigation efforts commenced immediately. A chronology of significant events that took place at the site starting from placement of the landslide dam up to the breach of the dam portion in front of Tung lake in July 2010 is presented in Figure 4. These events include the following:

(i) Fresh topographical surveys of the landslide, landslide dam, and Karli lake areas were completed, and $2 \mathrm{~m}$ contour interval maps were prepared by the end of December 2005 (see Figure 5). Figure 5(a) also shows the points of investigation of the authors' study conducted from April 2006 to May 2007 (details are elaborated in later sections of this paper) and the rim of $300 \mathrm{~m}$ long erosion gully that developed between December 2008 and June 2009 (as noted in $[10,11])$. The thick contour (1368 m AMSL) in Figure 5(b) represents the minimum crest elevation of the landslide dam in its natural state (after Abeer [12]). Karli lake was expected to rise to this elevation without any corrective works

(ii) For transportation of earth moving equipment, a $2.4 \mathrm{~km}$ long access track was constructed from the existing road to Tung lake (completed on February 11, 2006) and another $2.2 \mathrm{~km}$ long track from Tung to Karli lake (completed on March 1, 2006) (iii) The WAPDA established a data monitoring system associated with this landslide dam, including daily upstream flows of the two channels, their combined downstream flow, variations in surface elevations of the two lakes, and the daily rainfall. This data was collected for a total of 312 days between December 26, 2005, and December 31, 2006. The approximate locations of the data collection points are shown in Figure 6

(iv) A $130 \mathrm{~m}$ long spillway, $11.5 \mathrm{~m}$ deep with base width of $4.5 \mathrm{~m}$ and elevation of $1235 \mathrm{~m}$ AMSL, was excavated through the dam debris in front of Tung lake. The overtopping flow through the spillway began as soon as it was fully excavated on February 11, 2006. The overflow of the lake from Tung spillway and seepage through that part of the dam body caused washing out of the fines through surface erosion and piping over the next about 4 months. Resultantly, lake surface elevation was reduced to $1228 \mathrm{~m}$ AMSL by June 20, 2006. Figure 7 shows the cross-sectional dimensions of the Tung spillway at its deepest excavation point and a picture of the overtopping flow through Tung spillway. Although signs of seepage erosion were noticed later, Tung lake experienced a near steady flow across the dam over the next 4 years

(v) A $708 \mathrm{~m}$ long spillway, with three distinct segments, was excavated through the dam debris blocking the Karli channel (see Figure 8(a)). The first $477 \mathrm{~m}$ long segment was excavated at least $15 \mathrm{~m}$ east of toe of the main landslide with a maximum base elevation of $1352 \mathrm{~m}$ AMSL and an average base slope of $1: 11$. The crosssection of maximum cut location along this segment is shown in Figure 8(b), and photographs of the same section are shown in Figures 8(c) 


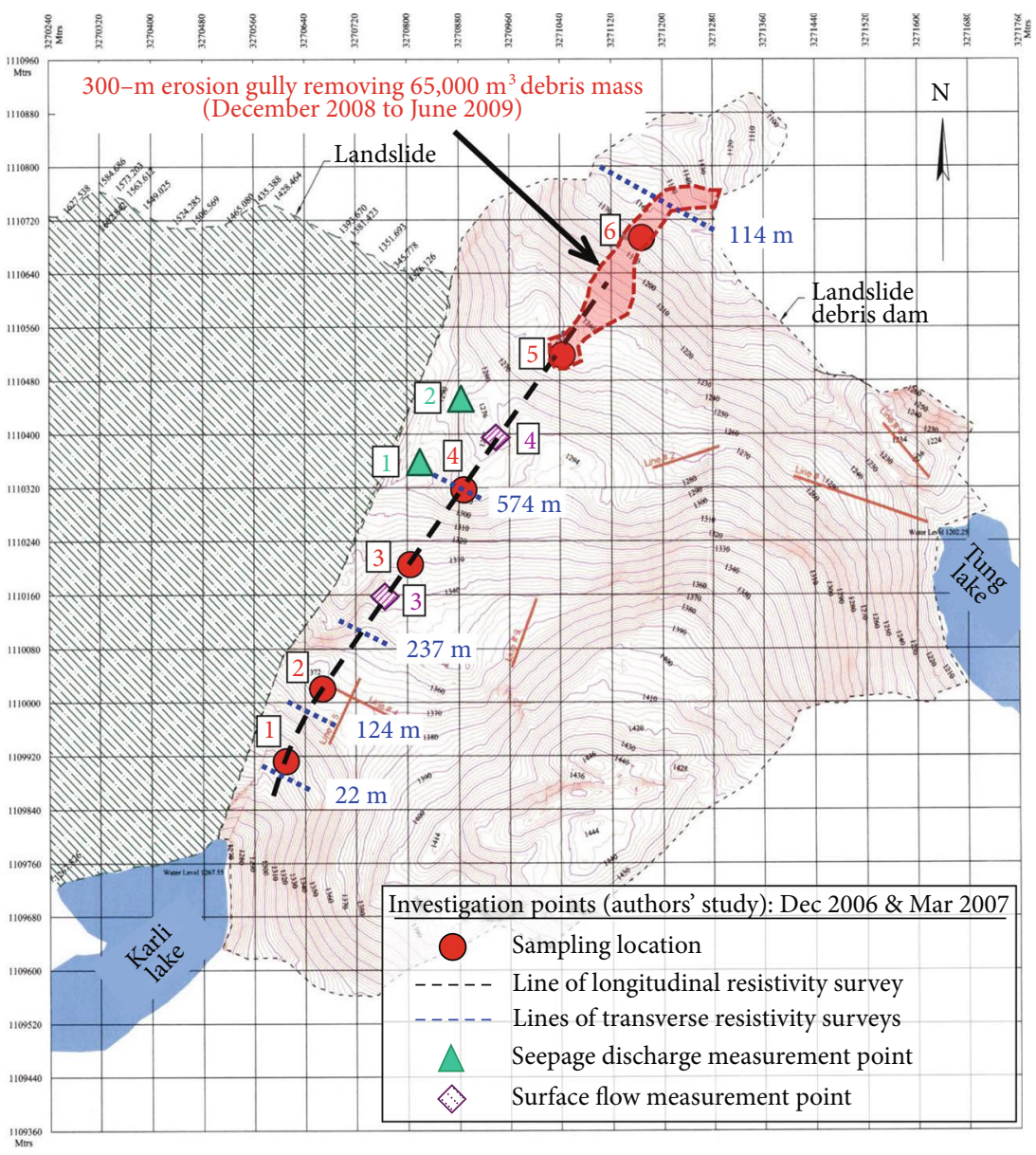

(a)

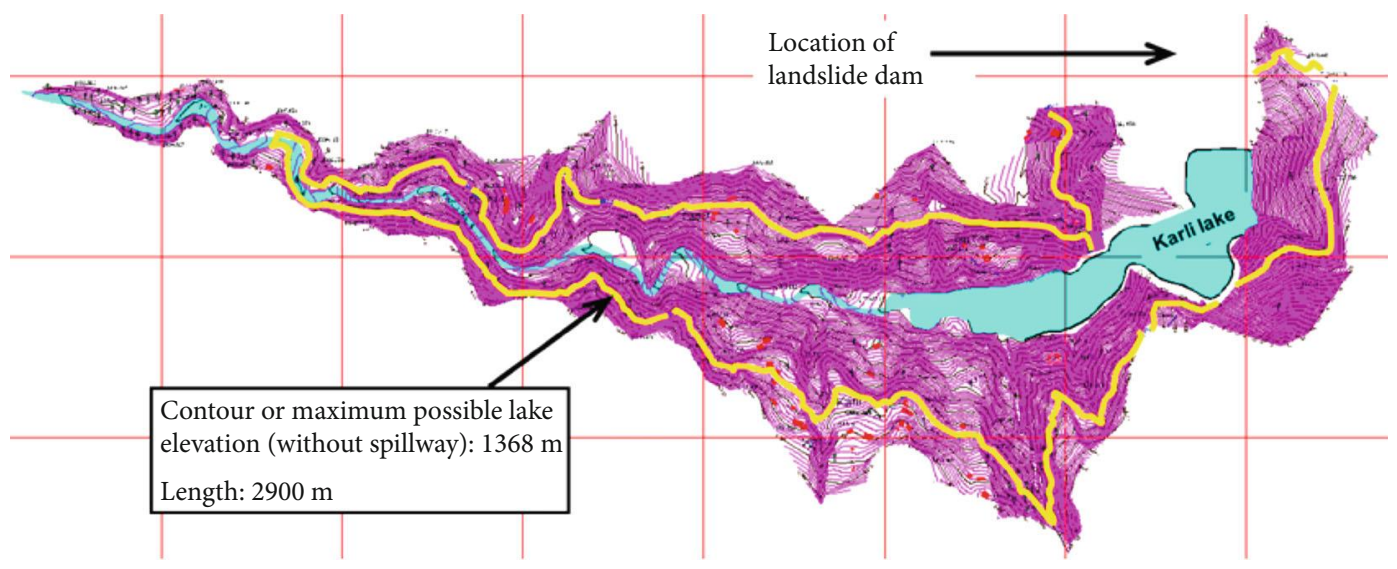

(b)

FIgURE 5: (a) 2 m contour interval topographical map of Hattian Bala landslide dam showing the field investigation points of the authors' study (measurements made in December 2006 and March 2007) and the rim of erosion gully (developed between December 2008 and June 2009); (b) $2 \mathrm{~m}$ contour interval topographical map of Karli lake area (adapted from [12]).

and 8(d). In particular, Figure $8(\mathrm{~d})$ shows the spillway bed treatment of this segment by placing boulder- and cobble-sized sandstone rocks from the site. This was done to control rapid surface erosion, especially during a flash flood event. Part of the dam debris excavated from this segment was dumped on the west side in the natural low- est crest elevation along the toe of the landslide to add to its stability. The middle $71 \mathrm{~m}$ long segment had a natural slope of $1: 2$ along the spillway alignment. To ensure that the overtopping flow of water from the first $477 \mathrm{~m}$ long segment was directed to the third $160 \mathrm{~m}$ long segment, embankments were built on the east and west 


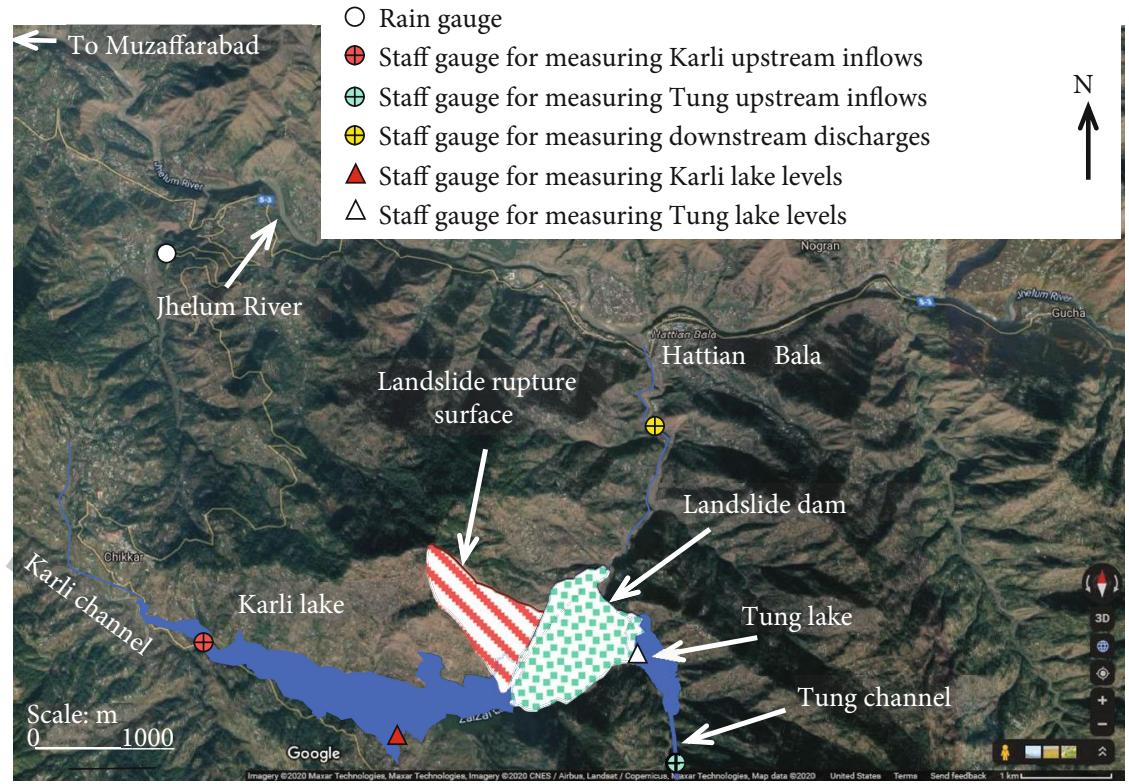

FIGURE 6: Hydrological data monitoring locations marked on the topographical map of the area (data collection period: December 26, 2005, to December 31, 2006) [13].

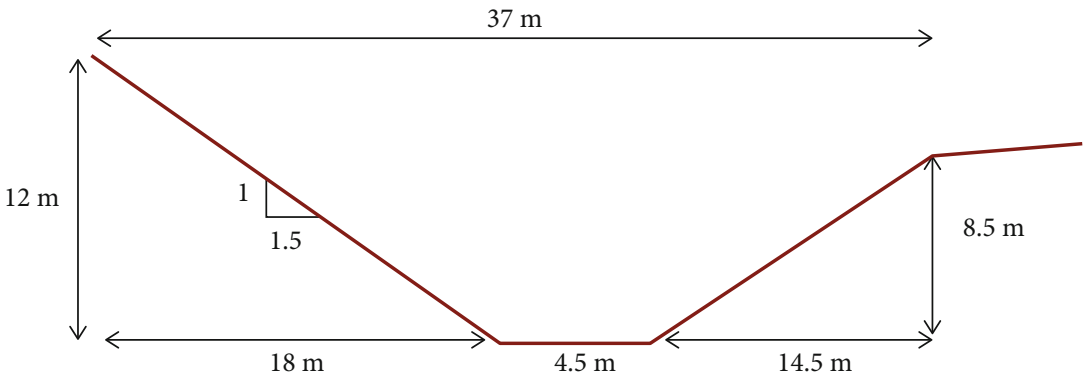

(a)

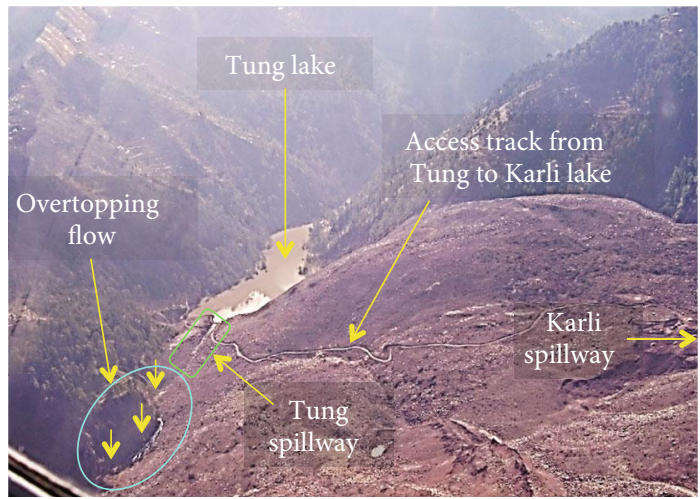

(b)

Figure 7: (a) Cross-section of the deepest spillway cut along the landslide dam portion blocking Tung lake; (b) photograph of Tung lake overtopping newly excavated spillway (February 12, 2006).

sides of this middle segment from part of the excavated dam debris. The third segment was relatively flat, excavated to the average base elevation of $1277 \mathrm{~m}$ AMSL (see Figure 8(e)). A total of about 1.1 million $\mathrm{m}^{3}$ of debris material was excavated during the construction of this spillway (vi) While Karli lake continued to fill to its capacity, multiple seepage points along the downstream slope of the dam developed in early February of 2007 (see Figures 5(a) and 9). Karli lake filled to its capacity and started overflowing through the spillway on March 31, 2007 (see Figure 9) 


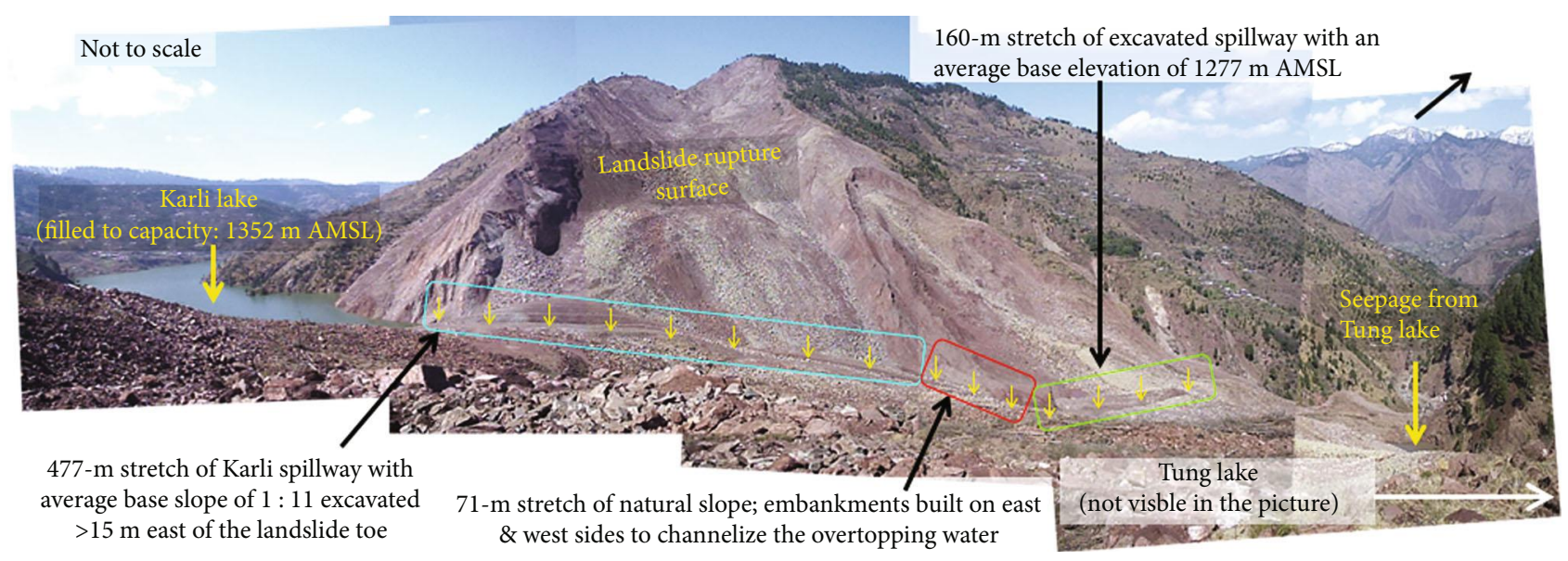

(a)

$161.6 \mathrm{~m}$

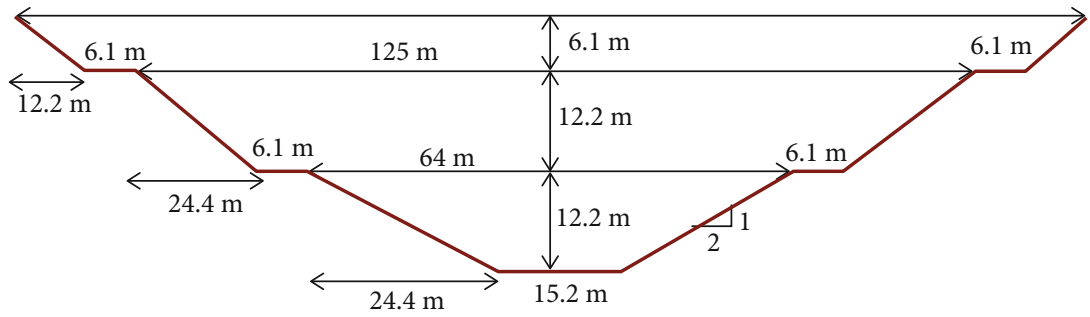

(b)

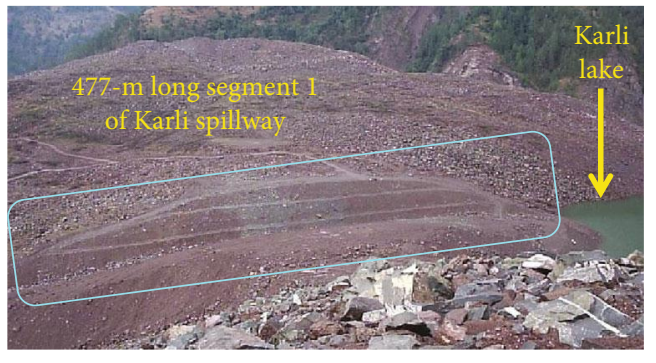

(c)

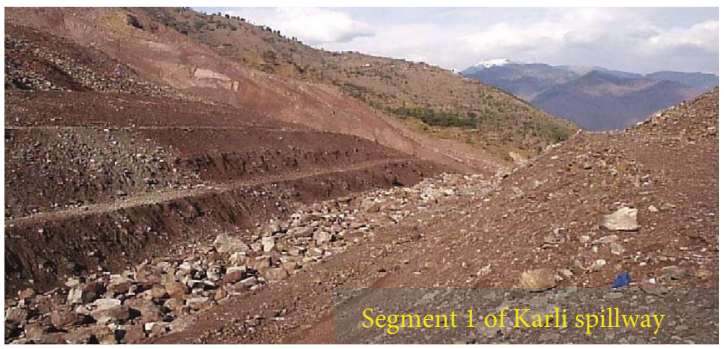

(d)

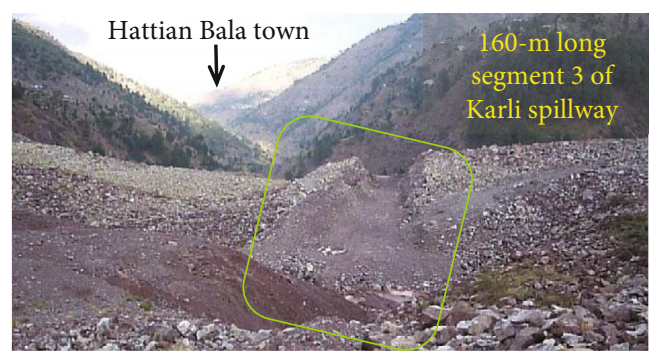

(e)

Figure 8: (a) Photomosaic showing complete view of the landslide rupture surface (scarp to toe), Karli lake, landslide dam portion blocking Karli channel, Karli spillway, and Tung lake seepage location (31 March 2007); (b) cross-section of segment 1 of the deepest spillway cut along the landslide dam portion blocking Karli lake; (c) photograph showing a complete view of segment 1 of Karli spillway (May 2006); (d) photograph showing bed treatment of Karli spillway segment 1 (May 2006); (e) photograph showing segment 3 of Karli spillway (December 2006). 


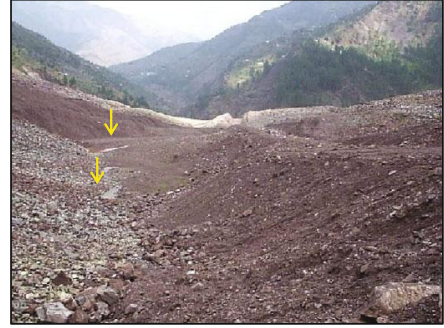

(a)

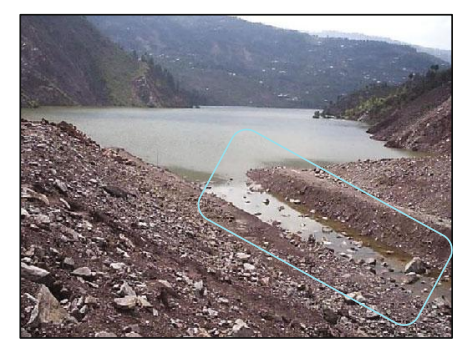

(b)

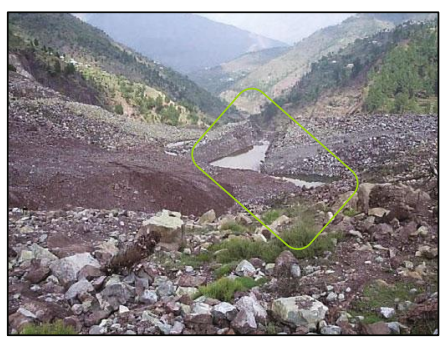

(c)

FIgURe 9: Photographs showing (a) locations of seepage points along the downstream slope of the dam (February 2007); (b) Karli lake filled to its capacity overtopping through segment 1 of Karli spillway (April 2007); (c) overtopping water from Karli lake flowing through segment 3 of Karli spillway (April 2007).

(vii) Over a period of the next 3 years, retrogressive erosion was intermittently observed along the downstream slope from the presence of sediments in the downstream flow, although no formal measurements were made until July of 2008

(viii) Quantitative measurements of creep deformation were made along the Karli spillway in longitudinal and traverse directions using Differential Global Positioning System (DGPS) in July and November of 2008 and in June and November of 2009, as reported elsewhere $[10,11,14,15]$. Deformation in the dam debris mass reported over this period was not significant (the crest subsided by $10 \mathrm{~cm}$ while the toe part heaved slightly up) except for a $300 \mathrm{~m}$ long erosion gully at the toe of the landslide dam that developed between November 2008 and May 2009, which detached approximately $65,000 \mathrm{~m}^{3}$ of soil mass (see Figure 5(a) for the location). The slakable nature of the dam material combined with heavy rainfall was found to be the cause of the deformation $[14,15]$

(ix) Due to incessant rains in early February of 2010, the water of the Karli lake breached the landslide dam on February 9, 2010, eroding 7.78 million $\mathrm{m}^{3}$ of debris mass and immediately draining about 36 million $\mathrm{m}^{3}$ of water from Karli lake (see Figure 10). The flushed debris mass was deposited along the downstream stretch of Karli channel [11]. This breach caused the loss of one life and two dozen houses on the downstream stretch of Karli channel [10]. The lake ultimately reduced to a surface elevation of about $1298 \mathrm{~m}$ AMSL over the next decade

(x) The unprecedented floods caused by the monsoon rains in 2010 breached Tung lake as well around the end of July 2010. The lake surface elevation was reduced by $15 \mathrm{~m}$ [11], and it has been flowing steadily since then

(xi) An event, not immediately related to the landslide dam itself, but an ultimate consequence of the drawdown of the Karli lake, combined with the disturbance of the pore water pressure equilibrium introduced by unusually heavy rainfall, was reported by Basharat et al. [16]. A translational landslide was triggered on October 24, 2014, upstream of the dam, part of which transformed into earth flow (see Figure 10(c) for the location). This earth flow destroyed 3 houses along the scarp of the landslide and rendered many others to potential risk of future damage

\section{Authors' Contributions to Hattian Bala Case Study}

The investigations and studies regarding this case study, cited in the foregoing, can be broadly classified into two categories: (1) preliminary investigations to immediately propose measures for minimizing the hazard potential and (2) monitoring projects intended to quantify the evolving scenario at the site. Because of their inherently rapid forming process and ephemeral nature, combined with their complex composition, this general approach of dealing with landslide dams is rather appropriate. Nonetheless, each case has its distinct peculiarities and settings, requiring the use of engineering judgement and consideration of alternative methods of investigation.

The authors' investigations and analyses on the Hattian Bala landslide dam span over a period of 13.5 months (April 1,2006 , to May 15, 2007). Upon review of literature on the topic, reassessment of the above cited investigations, and a 


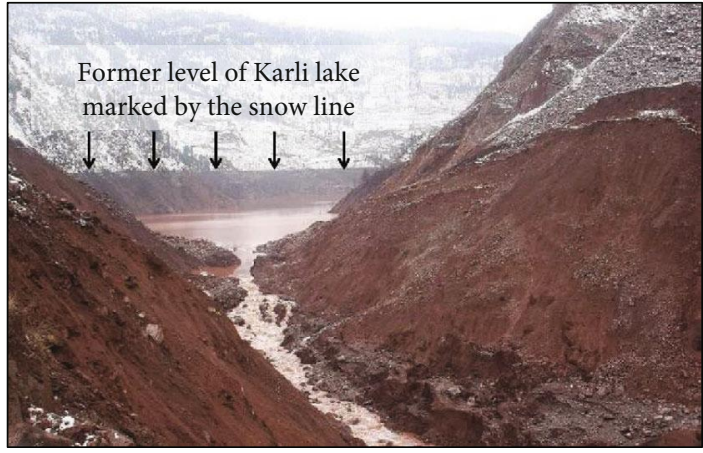

(a)

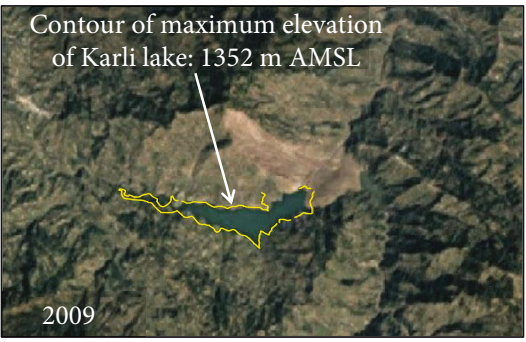

(b)

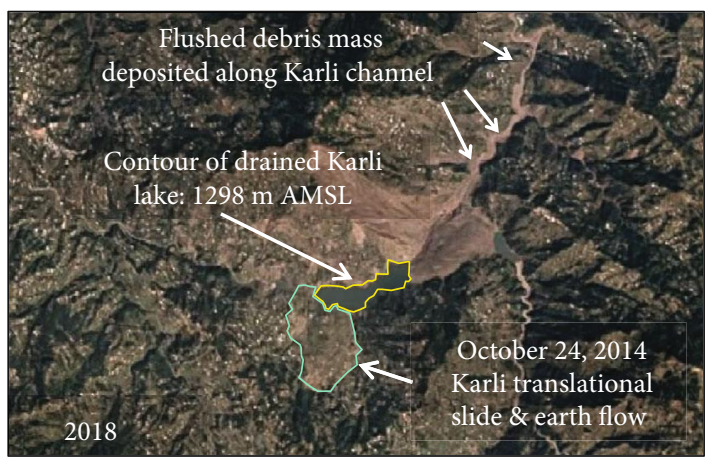

(c)

FIGURE 10: (a) Photograph showing the breached landslide dam in front of Karli lake (after [17]; photo courtesy of Dr. Kausar from GSP, dated February 10, 2010); (b, c) Google Earth Timelapse imageries of the Hattian Bala landslide area (year 2009, before landslide dam breaching, and year 2018, most recent available) $[16,18]$.

week-long site reconnaissance in the first week of April 2006, the following observations were noted:

(i) The recommendations proposed in the preliminary studies were based on geotechnical investigations limited to surface observations and seismic surveys at random locations. The soil and rock sampling for laboratory testing was also done from the dam surface. This did not assist in developing a true subsurface picture of the landslide dam. With the excavation of segment 1 of Karli spillway nearing its completion, the subsurface profile of the most critical part of the landslide dam had now been exposed (average cut depth $>20 \mathrm{~m}$ ), and more representative samples could be collected for laboratory investigations

(ii) Due to the overall devastated infrastructure and colossal loss of life in the entire region, the immediate priority of the authorities during the early months post this October 8, 2005, earthquake event went to rescue, relief, and rehabilitation activities including opening of communication infrastructure. That, combined with extreme difficulties in transporting field investigation equipment, likely forced the preliminary study teams to make simplifying assumptions regarding important geotechnical parameters (e.g., topographic profiles, $k, \phi^{\prime}$, and $c$ ). Ranges of assumed parameters were used in the seepage and slope stability analyses to hypothesize different anticipated scenarios. In reaching their conclusions, more reliance had to be placed on the expertise of geotechnical engineers and geologists with prior experience on similar events

(iii) The model of the landslide dam, prepared for numerical simulations in seepage analysis, did not represent the profile of the dam based on the updated topographic data

(iv) The heterogeneous nature of the landslide dam, coupled with increasing size and volume of water in Karli lake and the evolving processes of consolidation, seepage, and erosion, necessitated in-depth field and laboratory investigations to decide about the monitoring mechanism and prepare an early warning system for the downstream population in case of emergency

(v) Additional data, particularly the streamflows, lake elevations, and daily precipitation, was being compiled in the year 2006. An objective seepage analysis was possible by integrating this new set of information

These observations made it clear that the use of alternative investigation tools was required towards a more rational analysis.

4.1. Materials and Methods. The main focus of the authors' work was the stability study of the landslide dam portion blocking the Karli channel (then turned into a lake), since it was a 


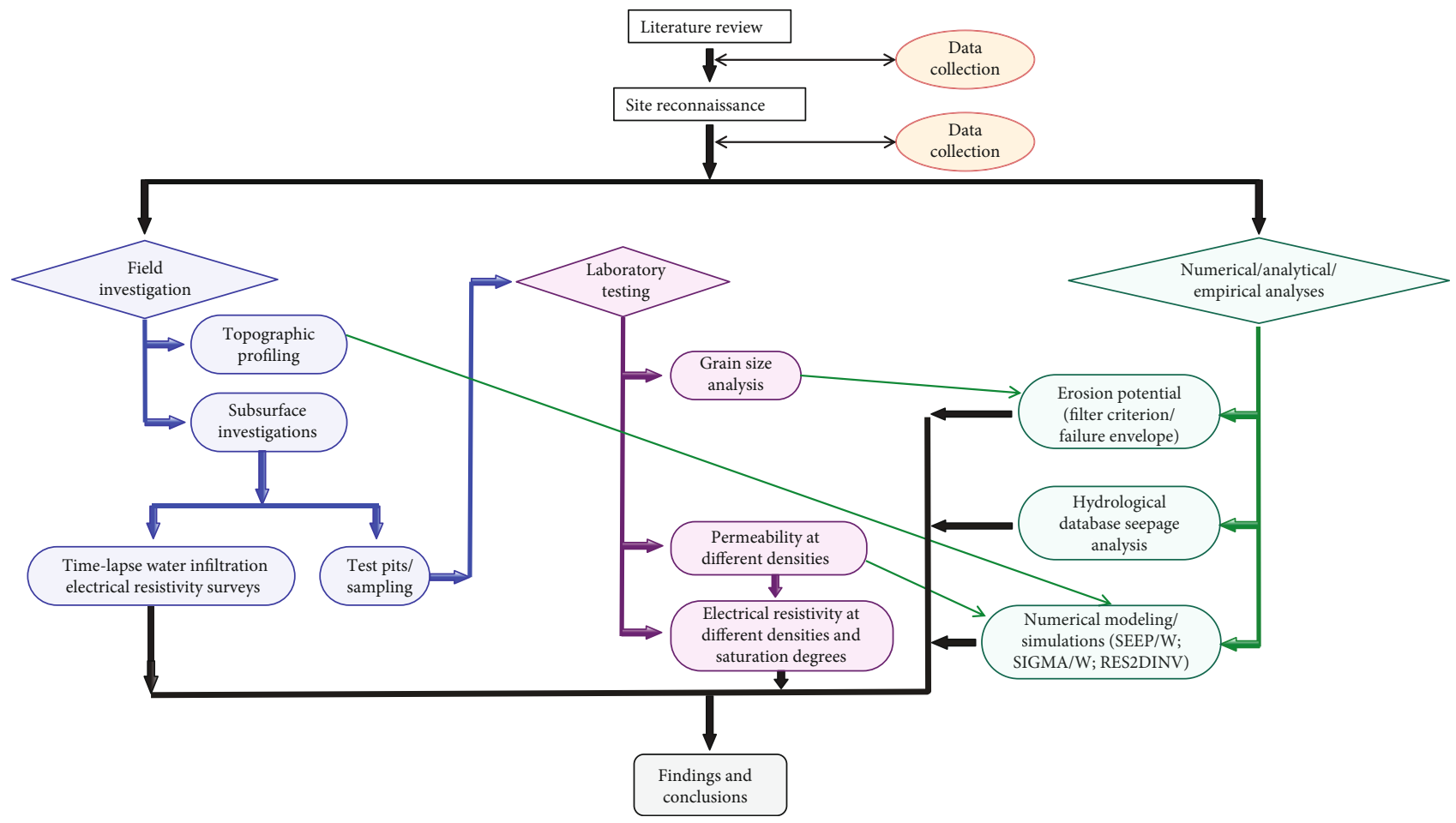

Figure 11: Flow chart of the authors' investigations for Hattian Bala landslide dam.

significant evolving hazard. The decision regarding the employment of investigation methods was taken based on their feasibility and reliability, vis-à-vis limitations of accessibility to the site, and the size and scale of the landslide dam. Investigations were aimed at determining the subsurface conditions including the stratigraphy, saturation levels, and seepage conditions affecting the dam stability. A flow chart explaining the investigation methodology adopted in this study is shown in Figure 11. The field investigations were done in two phases, with each phase spanning over a period of about 2 weeks (phase 1 in November/December 2006 and phase 2 in February/March 2007). The following is a summary of the investigations and analyses performed for this study and sets of information relevant to each method and testing approach adopted or analysis performed during this entire process (see Figure 5(a) for locations of field investigation points).

4.1.1. Topographic Surveys. Using a DGPS, and the pre- and postevent topographic maps, five transverse and one longitudinal surface topographical profiles were obtained along the Karli spillway (see Figures 5(a) and 12). These locations and alignments were selected for the field electrical resistivity surveys planned in the two phases mentioned above and their subsequent numerical simulation and computer modelling.

Since the newly constructed spillway was approximately aligned with that of the preevent trace of the Karli channel, it was logical to predict that when the Karli lake water, entering from the upstream slope of the dam, seeps through its main body, it would concentrate beneath the bed of the spillway. This formed the basis for alignment of the longitudinal survey line.
Locations of the transverse survey lines were selected at critical points along the spillway bed to validate the results of the longitudinal surveys and to support other relevant subsurface investigations. Three of these transverse survey lines were selected over the first half of segment 1 of the spillway, under which the seepage would initiate. The location of the second survey line was selected close to the least elevation point of the $71 \mathrm{~m}$ long naturally sloping segment 2 , where the seepage water was expected to reappear along the downstream slope. The fifth location was selected near the toe of the landslide dam debris. This location was surveyed in the second phase of the field investigations, when the Karli lake was approaching its maximum capacity, so that any signs of the seepage water reaching that toe of the dam could have been investigated.

4.1.2. Sampling. For laboratory testing, bulk samples of matrix material were obtained from six locations along the bed of the open cut spillway (see Figure 5(a) for the locations). With such a large scale and quantity of the debris material, selective testing was a compulsion, rather than a choice. It was anticipated that under the static loading conditions, the overall deformations, in the dam body in short to medium term, would result from the seepage/piping and surface erosion, but not from the displacement of heavier and coarser fragments (i.e., boulders and cobbles), and that seepage would concentrate below the Karli spillway. Therefore, the laboratory investigations were focussed on the finer matrix collected from the spillway bed.

4.1.3. Time-Lapse Water Infiltration Electrical Resistivity Surveys. In general, the material classification of the debris mass of the dam was known from the prior investigations 


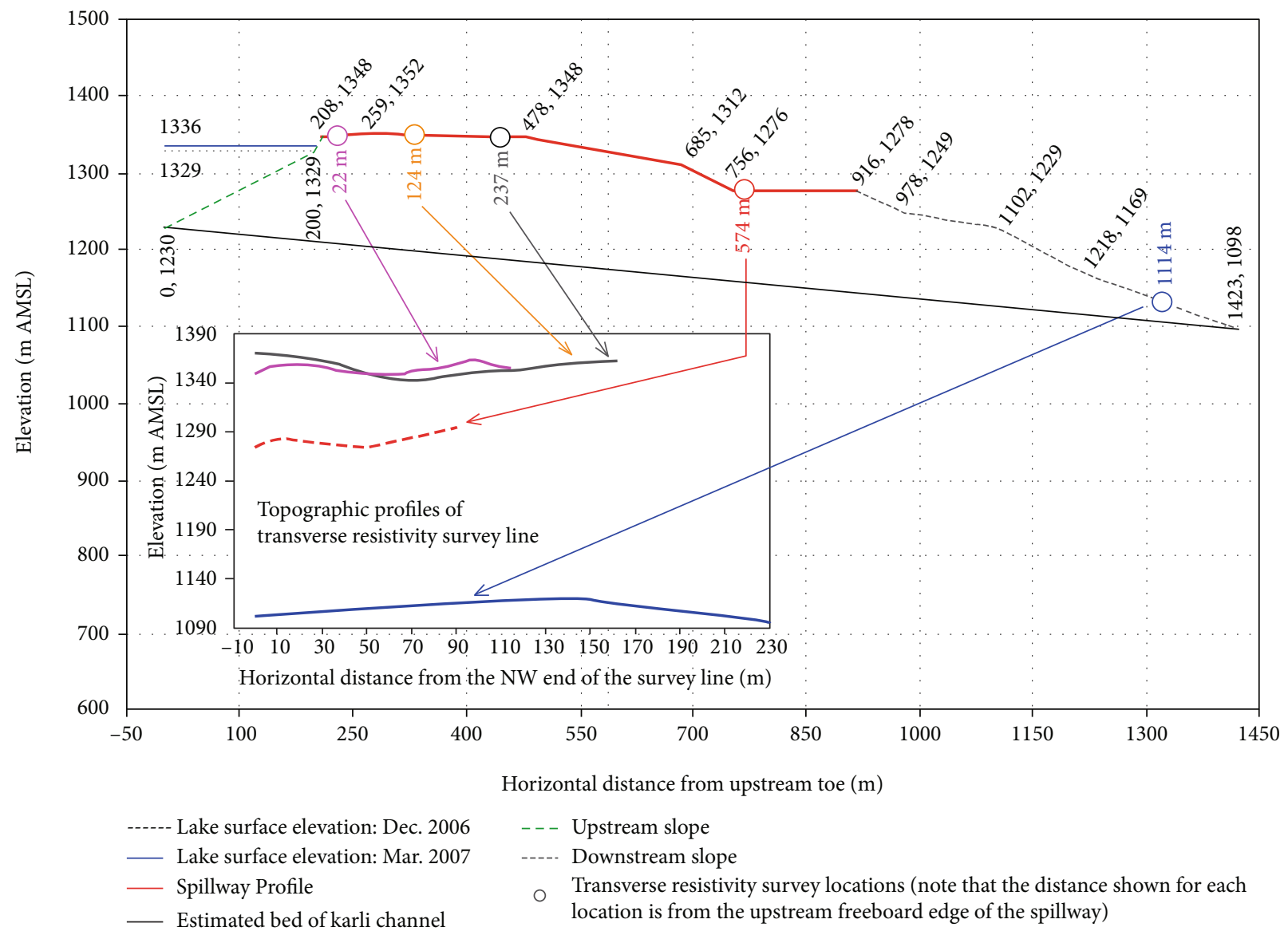

FIGURE 12: Surface topographic profiles of the lines for electrical resistivity surveys; the longitudinal survey line along the Karli spillway and the transverse resistivity locations are shown in the main graph, while the transverse survey lines at $22 \mathrm{~m}, 124 \mathrm{~m}, 237 \mathrm{~m}, 574 \mathrm{~m}$, and $1114 \mathrm{~m}$ from the start point of the spillway are shown in the inserted graph.

and geological information gathered from the literature review. Therefore, in evaluating the subsurface conditions, the primary focus was maintained on the permeability assessments and the evolving states of the degree of saturation and material densities. This was accomplished via a series of two-dimensional (2D) electrical resistivity time-lapse water infiltration surveys (with a time-lapse of 3 months) along the survey lines shown in Figures 5(a) and 12. A 2D model is relatively accurate for the subsurface imaging where resistivity changes are common in the vertical and horizontal directions along the survey line.

The surveys include one longitudinal and four in the transverse direction in phase 1 and one repeat of the longitudinal survey besides one transverse survey near the toe end of the dam in phase 2 . The second longitudinal survey was conducted as a series of resistivity imaging in time and space to determine the ingress of water from the Karli lake into the dam body.

The surveys were performed by employing the procedure outlined in [19] and by using the Wenner (alpha) electrode array. A 4-electrode resistivity meter system was used. The test parameters are shown in Table 1. Figure 13 shows the electrode locations marked before the field survey and the electrical resistance readings being recorded at the site.

Wenner (alpha) has a simpler arrangement vis-à-vis the length of the longest survey line, the terrain difficulty at the site, and its property of yielding higher signal strength and better ver- tical resolutions than most of the other arrays [20]. Two outer current and two inner potential electrodes are placed with equal mutual spacing $(\mathrm{ES}=a)$ at the start of the survey line, and the resistance of the subsurface is obtained via a resistivity meter. After each reading, the array is advanced along the survey line by a distance " $a$," and the next reading is recorded. This continues until the electrode array has reached the end of the survey line. The whole procedure is then repeated for the next sequence with the electrodes' mutual spacing ES doubled to " $2 a$ " while maintaining the advancing distance between two consecutive readings $=1 a$. The sequences are continued until the electrode spacing $\mathrm{ES}=L / 3$, where $L$ is the length of the survey line.

The raw readings of the resistivity meter are the resistance values used to calculate the "apparent" resistivity values of the subsurface, from which the "true" resistivity is determined via an "inversion" problem. Inversion methods attempt to determine a model for the subsurface whose response agrees with the measured data [20]. The RES2DINV module in the Geotomo software package, with its inbuilt inversion feature, was used for modelling of the field acquired data. In the cellbased method used by the RES2DINV, model parameters are the resistivity values of model cells, while the data are the measured apparent resistivity values. The mathematical link between the model parameters and the response for $2 \mathrm{D}$ resistivity models is provided by finite element methods [20]. 
TABLe 1: Test parameters of the field electrical resistivity surveys at the Hattian Bala landslide dam.

\begin{tabular}{|c|c|c|c|c|c|c|}
\hline Survey location & $\begin{array}{l}\text { Length of survey } \\
\text { line }(\mathrm{m})\end{array}$ & $\begin{array}{c}\text { No. of } \\
\text { sequences }\end{array}$ & $\begin{array}{c}\text { No. of data } \\
\text { points }\end{array}$ & $\begin{array}{l}\text { Maximum investigation } \\
\text { depth }(\mathrm{m})\end{array}$ & $\begin{array}{l}\text { Initial electrode } \\
\text { spacing }(\mathrm{m})\end{array}$ & $\begin{array}{l}\text { Electrode } \\
\text { array }\end{array}$ \\
\hline \multicolumn{7}{|c|}{ Phase 1 (November/December 2006) } \\
\hline Longitudinal & 894 & 59 & 3675 & 155 & & \multirow{5}{*}{ Wenner alpha } \\
\hline Transverse at $22 \mathrm{~m}$ & 114 & 6 & 57 & 20 & & \\
\hline Transverse at $124 \mathrm{~m}$ & 150 & 8 & 100 & 26 & 6 & \\
\hline Transverse at $237 \mathrm{~m}$ & 162 & 9 & 117 & 28 & & \\
\hline Transverse at $574 \mathrm{~m}$ & 90 & 5 & 35 & 16 & & \\
\hline \multicolumn{7}{|c|}{ Phase 2 (February/March 2007) } \\
\hline Longitudinal & 894 & 59 & 3675 & 155 & 6 & \multirow{2}{*}{ Wenner alpha } \\
\hline Transverse at $1114 \mathrm{~m}$ & 234 & 26 & 1001 & 41 & 3 & \\
\hline
\end{tabular}

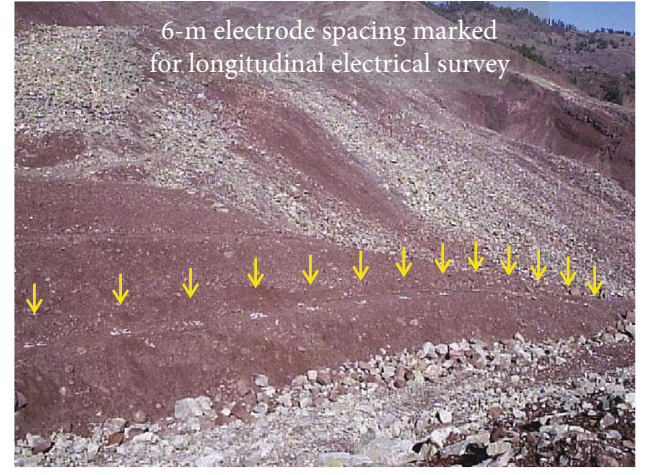

(a)

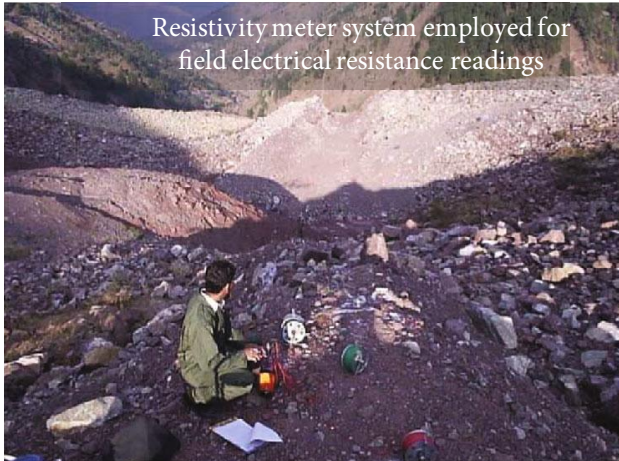

(b)

Figure 13: Field electrical resistivity survey in progress along the longitudinal survey line of the Karli spillway. The pictures illustrate (a) the marking of the electrode locations and (b) the resistivity system.

TABLE 2: RES2DINV modelling parameters for the Hattian Bala landslide dam.

\begin{tabular}{lcc}
\hline Category & Method used & Remarks \\
\hline Inversion & Combined inversion method & Marquardt (or ridge regression) and Occam (or smoothness-constrained) \\
Model discretization & Extended model method & Model extended to survey lines' edges \\
Topographic modelling & Distorted finite element grid & Uniform distortion \\
\hline
\end{tabular}

A summary of the methods used in the RES2DINV program to build the subsurface pseudosections is given in Table 2. To determine true resistivity values, a "combined inversion" method was selected, which is used in situations where data sensitivity values of model cells are distorted by large resistivity variations [20]. By combining "Marquardt" and "Occam" inversion methods, distortions found due to large resistivity variations in the model were reduced. To account for the topographic variations along the survey lines, the coordinates, shown in Figure 12, were included as part of the input data. A "distorted finite element grid with uniform distortion" was selected for the topographic modelling. This enabled matching the surface nodes of the mesh to the actual topography. With this option, nodes below the surface (and the model layers) shifted by the same extent as the surface nodes.

4.1.4. Laboratory Investigations. The samples of matrix material were used in the following laboratory tests: (i) Classification Tests. Including the grain size analysis and the Atterberg limit determination following the ASTM Standards [21-23] for textural classification based on the Unified Soil Classification System (USCS) [24]

(ii) Erosion Potential Assessment. Additional grain size analyses towards employing an empirical approach for the assessment of erosion potential (detailed methodology is explained in a separate subsection below)

(iii) Permeability Tests. Performed over a range of selected dry densities following the ASTM Standard [25] (the $k$ values from these tests were used in the seepage analysis, explained later) (see Figures 14(a) and 14(b) for the testing arrangement)

(iv) Laboratory Electrical Resistivity Tests. Performed as per the ASTM Standard [26]. The adopted testing methodology is detailed below. 
The electrical resistivity values determined from the field tests are characteristic not only of the type of the subsurface geomaterial but also of its dry density $\left(\rho_{\mathrm{d}}\right)$ and the degree of saturation $(S)$ [20]. The saturation levels within different zones below the field survey lines (which are also an indication of the seepage trends) could, therefore, be estimated if a correlation could be established between the field and laboratory determined resistivity values at different densities and degrees of saturation. Accordingly, a series of laboratory resistivity tests were performed on the samples of matrix material over a range of the same seven different densities used in the permeability tests and for five distinct degrees of saturation at each $\rho_{\mathrm{d}}$ (i.e., $S=20 \%, 40 \%, 60 \%, 80 \%$, and $100 \%$ ). A laboratory resistivity box $(6.2 \mathrm{~cm} \times 3.91 \mathrm{~cm} \times 22.9 \mathrm{~cm})$ was used to house the calculated quantities of the sample and water to achieve each $\rho_{\mathrm{d}}$ and $S$. Each sample was compacted in layers in a static compaction machine (see Figure 14(c)). The predetermined quantity of water was evenly added for the desired degree of saturation, and the resistivity box was placed in the vacuum chamber for about 30 minutes to allow uniform distribution of water within the sample. The resistance was measured with a resistivity meter after connecting it to the box with the current and potential electrodes embedded in the prepared sample (see Figure 14(d)). The resistivity $(\rho)$ values were then calculated using the following expression:

$$
\rho=R \frac{A}{a}
$$

where $R$ is measured resistance, $A$ is the cross-sectional area of the sample perpendicular to the current flow $(6.2 \mathrm{~cm} \times 3.91$ $\mathrm{cm}$ ), and $a$ is the inner electrode spacing [26]. Since these are apparent resistivity values, the calibrations for the field densities and degrees of saturation in different zones of the subsurface were also performed using the apparent resistivity values from the field

\subsubsection{Empirical Approach for the Assessment of Erosion} Potential. A common approach to assess the vulnerability of a dam to internal erosion is to apply the filter criteria in the transition areas from fine to coarser material [27]. This method of analysis was not appropriate for a naturally deposited heterogeneous landslide dam without developing a subsurface picture and accurately locating the zones of such transitions within the dam body. Based on the suggestions by Meyer et al. [28], the empirical approach of comparing the grain size distribution curves of the matrix materials from the six sampling locations on the landslide dam with Sherard's failure envelope [29] was adopted. This envelope was drawn from the analysis of numerous embankment dams that exhibited failure due to internal erosion; the curves of the soils falling within this envelope provide inadequate internal filtering capability. The envelope and the comparison are shown in Results and Interpretations.

The filter performance of the landslide dam, as suggested by $D_{15} / D_{85}$ Kézdi [30], was also investigated. To explain this application, a filter criterion, commonly expressed as $D_{15} /$ $D_{85}$, is often used in the soil drainage problems, including the selection of materials for erosion-free drainage through the embankment dams and the retaining walls, etc. Here, $D_{15}$ is the particle size corresponding to $15 \%$ finer of the grain size distribution curve of the coarse material (also termed as the filter), whereas, $D_{85}$ is the size corresponding to $85 \%$ finer of the grain size distribution curve of the retained or protected finer soil (also termed as the base). For the embankment dams to be stable against internal erosion, the $D_{15 \text {,filter }} / D_{85 \text {,protected soil }}$ ratio of its material should be less than 4 to 5 .

In applying this criterion to the matrix samples from the landslide dam, the grain size distribution curve of the whole material of each sample was separated at 6 different particle sizes $(0.15 \mathrm{~mm}, 0.43 \mathrm{~mm}, 0.85 \mathrm{~mm}, 2.00 \mathrm{~mm}, 4.75 \mathrm{~mm}$, and $9.53 \mathrm{~mm}$ ). Thus, a total of 36 separations were made for the 6 samples. For each separation, the complete coarser fraction was treated as the filter material and the entire remaining finer fraction was considered as the base or protected material. Separate grain-size distribution curves were drawn for the filter and base fractions. Then, $D_{15}$ of the grain size distribution curves of the filter and $D_{85}$ of the grain size distribution curves of base fraction were determined. Figure 15 illustrates the method of determining the $D_{15} / D_{85}$ ratio for one of the 6 samples from the Hattian Bala landslide dam at a separation size of $0.15 \mathrm{~mm}$ between coarse and fine fractions. As shown, the grain size distribution curves of the coarse fraction (reddashed) and the fine fraction (blue-dotted) are plotted separately besides that of the whole sample (black-solid), and their respective $D_{15}$ and $D_{85}$ are determined.

In addition to the individual $D_{15} / D_{85}$ ratios at 6 separation points, the means of those 6 were also calculated for each sample as well as for each separation point. The values were compared against the filtering capability criteria mentioned above.

4.1.6. Hydrological Database Analysis. The WAPDA and the Metrology Observatory at Garhi Dupatta collected hydrological data during a total period of 371 days (from December $26,2005$, to December 31,2006$)$ via the monitoring system shown in Figure 6. The actual data from each gauge was collected for the number of days shown below (these data are plotted in Figures 16(a) and 16(b)):

(i) Daily Karli channel inflow: 312 days

(ii) Daily Karli lake surface elevation: 312 days

(iii) Daily Tung channel inflow: 312 days

(iv) Daily Tung lake surface elevation: 286 days

(v) Daily downstream discharge: 286 days

(vi) Daily precipitation records: 371 days (actual rainfall: 73 days)

In addition to the above data, with the new contour maps now available at $2 \mathrm{~m}$ intervals, the plan areas of the lake surfaces corresponding to each contour and the matching volumes of water in the two lakes were also calculated and utilized for this study (see Figure 16(c)). The key data of catchment areas for both the channels is given in Table 3. 


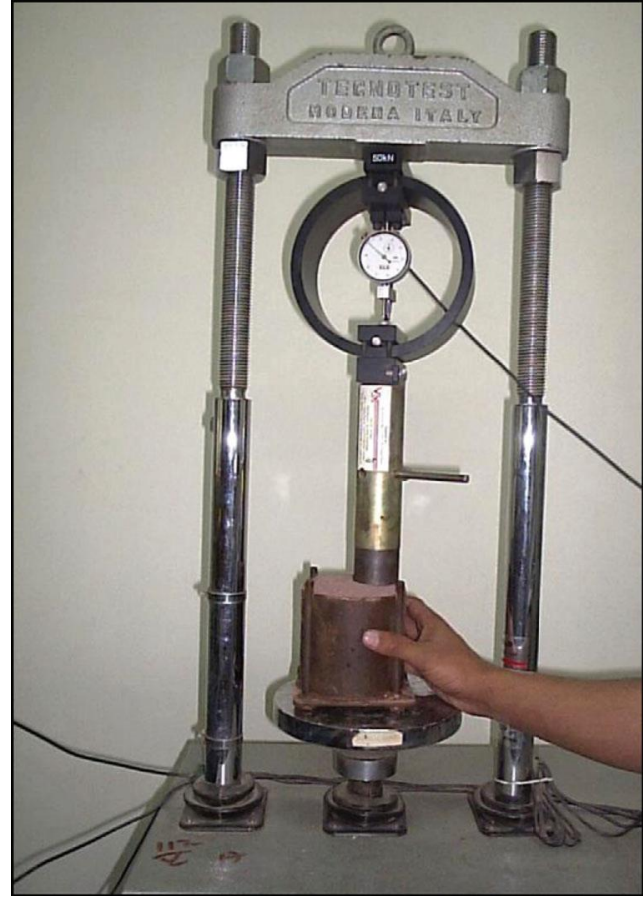

(a)

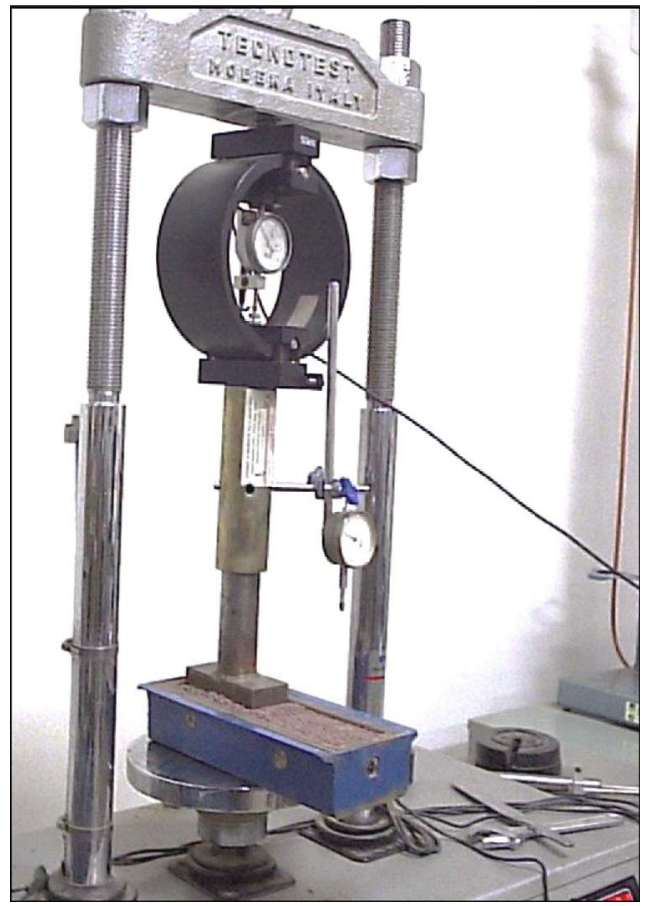

(c)

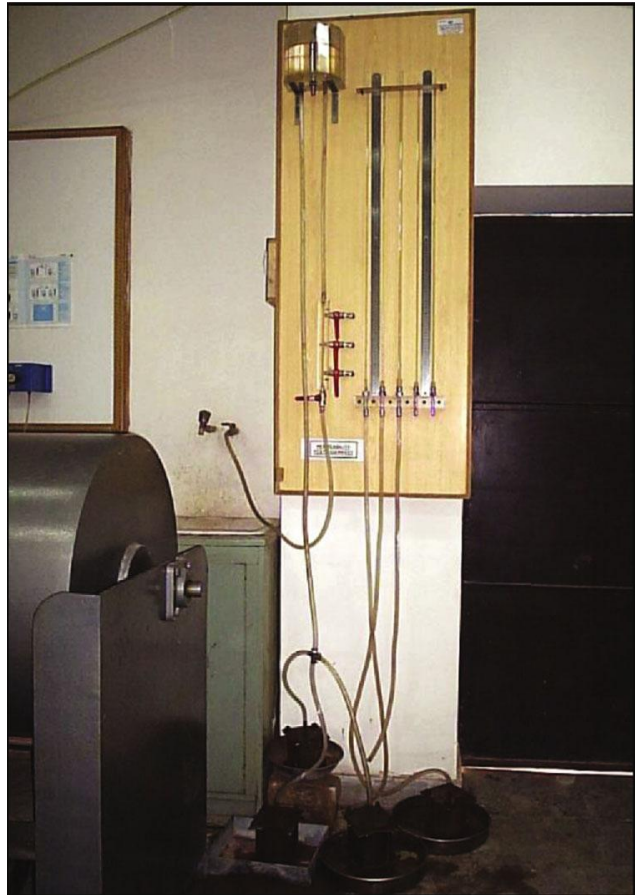

(b)

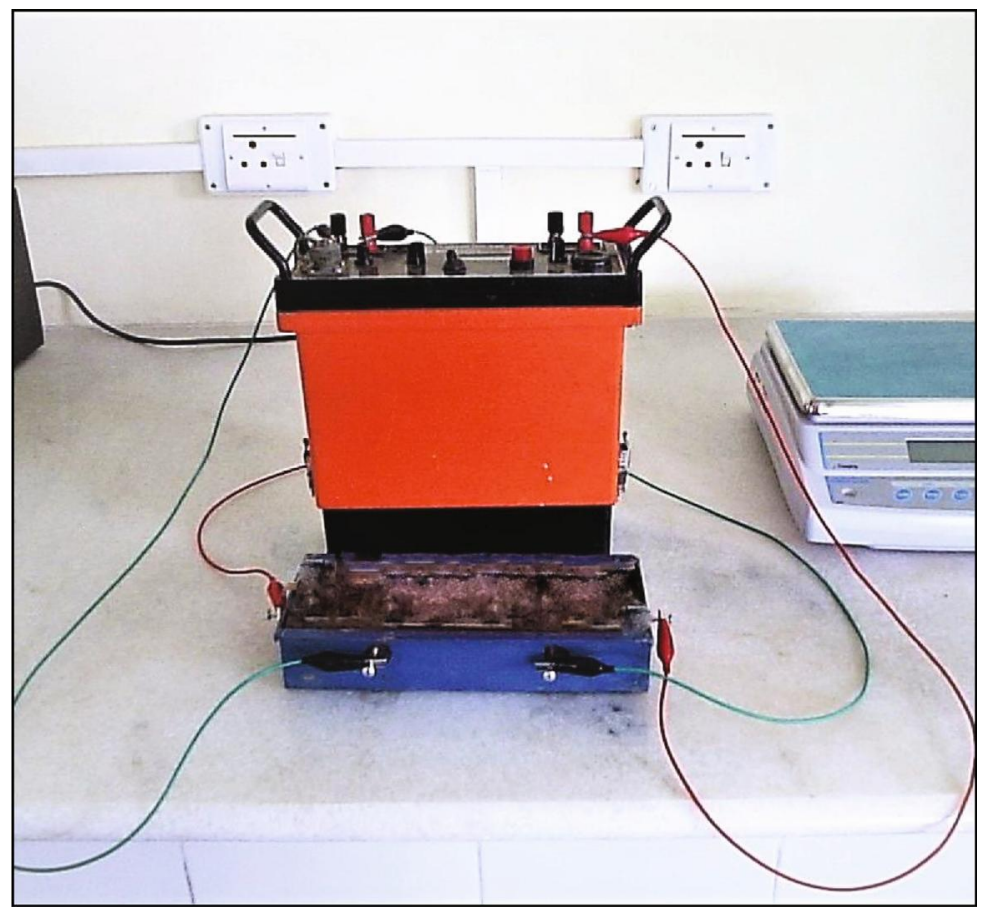

(d)

FIGURE 14: Selected laboratory tests on matrix material: (a) sample being compacted to the desired density in compaction-mold permeameter; (b) permeability test in progress on multiple samples; (c) sample being compacted to the desired density in the resistivity box; (d) resistivity box and sample connected to the resistivity meter with current and potential electrodes embedded in the sample. 


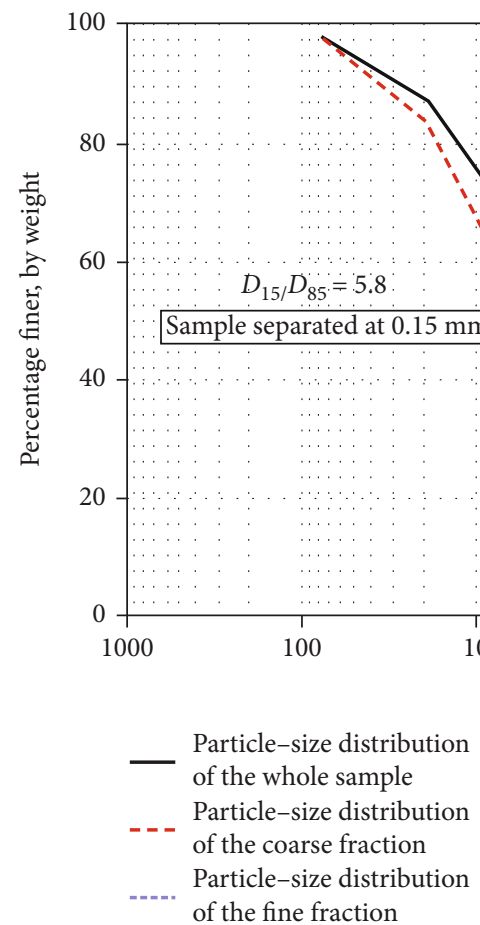

Figure 15: Illustration that shows the determination of $D_{15} / D_{85}$ of matrix sample material from the Hattian Bala landslide dam from its grain size distribution separated at $0.15 \mathrm{~mm}$ particle size.

Regardless of the extensive data mentioned above, the following significant, yet practical, limitations had to be dealt with in an effort to estimate the quantities of seepage into the landslide dam:

(i) The downstream discharge measurements were recorded at a location significantly distant from the toe of the landslide dam along the downstream stretch (see Figure 6). This implied possible contributions to the discharge from springs and nonperennial channels between the toe of the dam and the downstream measurement location, especially during the rainy days

(ii) Of the number of the catchment areas' springs listed in Table 3, the discharge data of those located between the upstream inflow measurement points of the two lakes and their respective interface with the upstream toe of the dam were not available

(iii) Runoff during the precipitation between the upstream measurement points and the upstream slope of the dam went ungauged into the lakes

(iv) The closest contour interval on the topographical maps of the catchment areas was scaled at $2 \mathrm{~m}$, whereas the daily fluctuations in the water levels in the Tung lake and the rise in that of the Karli lake were happening at the scale of millimeters. Therefore, the volume change measurements could not be compared with the inflow on daily basis with much accuracy (v) The nearest meteorological observatory at Garhi Dupatta was located nearly $30 \mathrm{~km}$ northwest of the site. Since the site was at a higher elevation, the daily temperature data recorded at that observatory were not very useful in calculations of the evaporation losses from the lakes

The following analyses were performed from the data graphically presented in Figure 16:

(i) Comparisons of the periodic lakes' levels with their respective inflows

(ii) Upstream inflows versus combined downstream discharges with effort to account for the precipitation

(iii) The influence of precipitation on the inflows and downstream discharge

(iv) Development of polynomial expressions representing the relationship between the plan areas $(y)$ and their corresponding surface elevations $(x)$ of the two lakes:

$$
\begin{aligned}
\text { Karli lake (with } \left.R^{2}=0.998\right): y= & 46.05 x^{2}-1.115 \\
& \times 10^{5} x+6.744 \times 10^{7}, \\
\text { Tung lake (with } \left.R^{2}=0.941\right): y= & 24.11 x^{2}-5.317 \\
& \times 10^{4} x+2.906 \times 10^{7}
\end{aligned}
$$




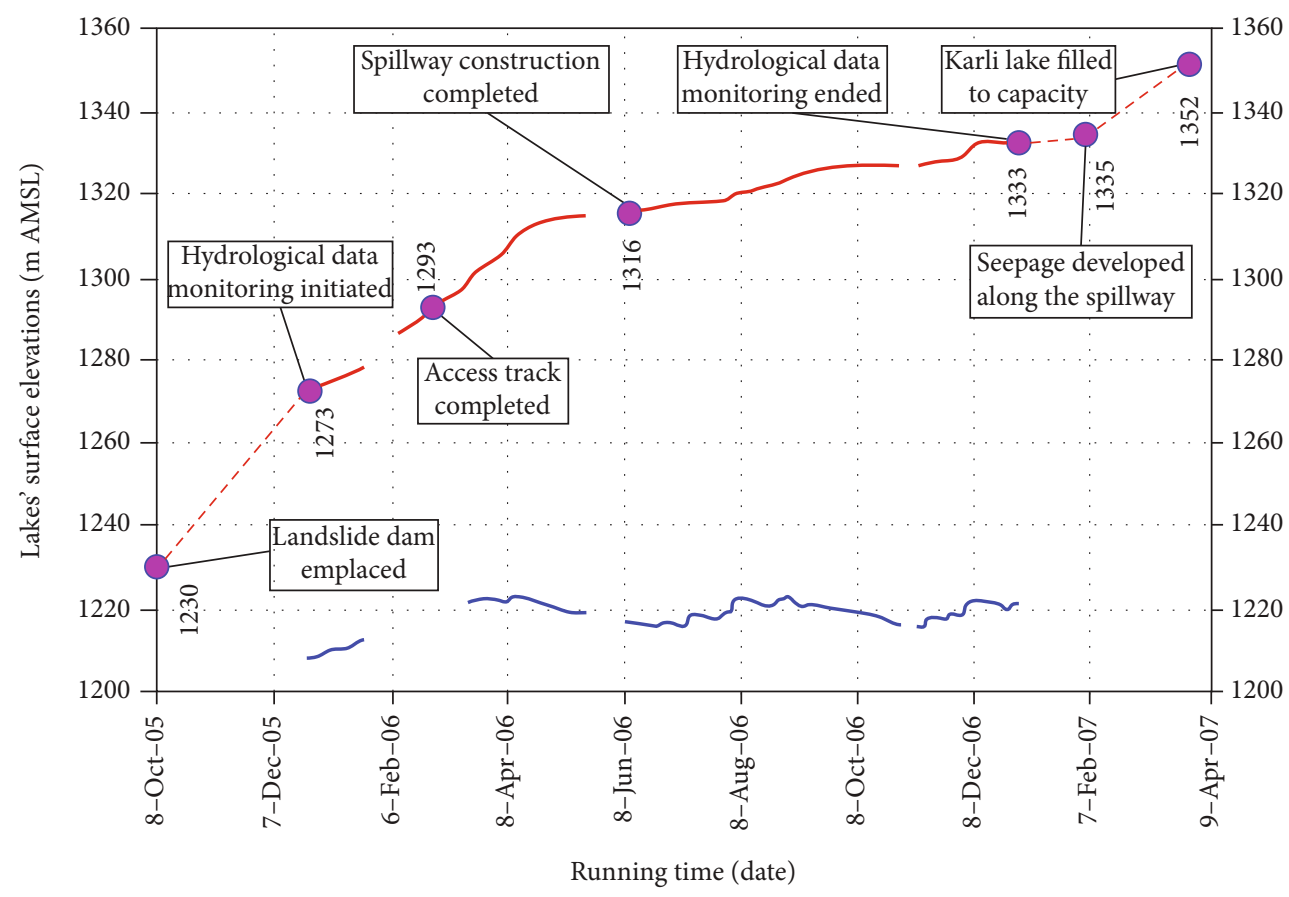

- Karli lake

- Key events of karli lake

_ Tung lake

(a)

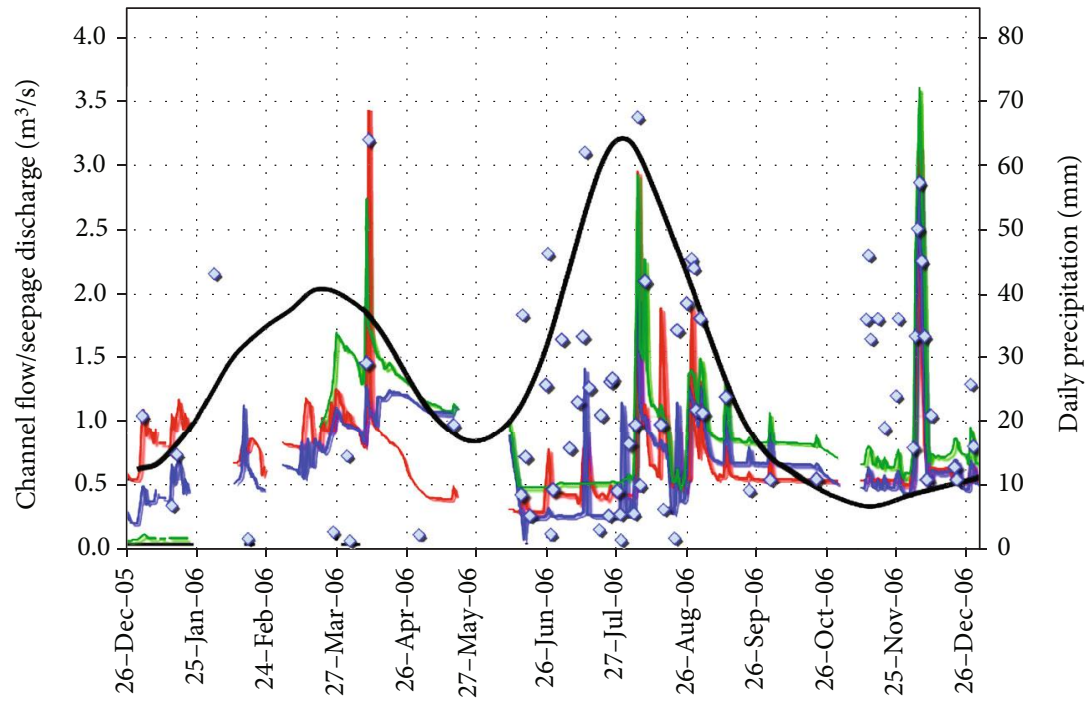

Running time (date)

- Karli channel inflow

- Downstream discharge

- Average historical precipitation

(January 1, 1980-December 31, 2016)

- Tung channel inflow

$\diamond$ Daily precipitation: monitoring period

(b)

Figure 16: Continued. 


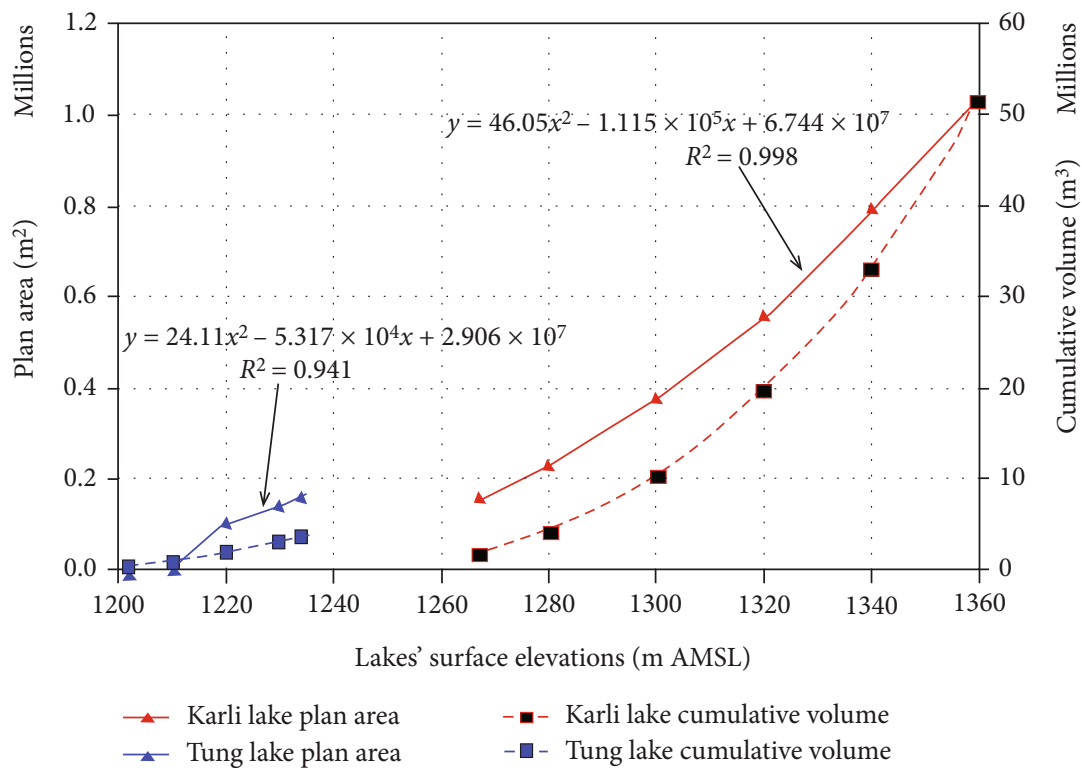

(c)

Figure 16: (a) Filling curves and lake periodic surface elevations for Karli and Tung lakes (significant events related to Karli lake are also shown): October 08, 2005, to March 31, 2007; (b) hydrological data including inflows of the two lakes and the downstream discharge from Hattian Bala landslide dam, daily precipitation in Hattian Bala area, and the average historical precipitation from NOAA [31]: December 26, 2005, to December 31, 2006; (c) plan area and corresponding cumulative volume vs. lake surface elevation for Karli and Tung lakes calculated from the contour maps.

TABle 3: Key data of catchment areas of Karli and Tung channels (after Hoeg et al. [8] and NESPAK and GSP [9]).

\begin{tabular}{lccc}
\hline Channel & Area $\left(\mathrm{km}^{2}\right)$ & Length $(\mathrm{km})$ & No. of springs \\
\hline Karli & 45 & 13 & 232 \\
Tang & 30 & 8 & 102 \\
\hline
\end{tabular}

(v) Comparisons of the daily increase in water volume of the Karli lake and fluctuation in the Tung lake based on the above expressions taking into account their daily inflows

(vi) Estimation of the seepage volume from the methodology is detailed below.

The seepage volume can be estimated if $Q_{\text {vol.dis. }}>Q_{\text {vol.cont. }}$ , where $Q_{\text {vol.dis. }}$ is the upstream inflow volume and $Q_{\text {vol.cont. }}$ is the volume between contours (i.e., the actual lake volume). To calculate the seepage volume in other cases, where $Q_{\text {vol.cont. }}>Q_{\text {vol.dis. }}$ or $Q_{\text {vol.cont. }}=Q_{\text {vol.dis. }}$, the ungauged flow must be determined. The general expression for the seepage discharge may be written as

$$
Q_{\text {out }}=Q_{\text {in }}+Q_{i ?}-\frac{\Delta h A_{\text {ave. }}}{\Delta t},
$$

where $Q_{\text {out }}$ is potential seepage discharge, $Q_{\text {in }}$ is the upstream inflow, $Q_{i}$ is the ungauged flow (e.g., rainfall on the surface area of lake + runoff from catchments), $\Delta h A_{\text {ave. }} / \Delta t$ is change in the storage, $\Delta h / \Delta t$ is the periodic change in the height of water in the lake, and $A_{\text {ave. }}$ is the average plan area with respect to $\Delta h / \Delta t$. Since the measuring interval was 24 hours, converting equation (3) from the rate of volume to volume basis yields

$$
Q_{\text {out }} \Delta t=\left(Q_{\text {in }}+Q_{i ?}\right) \Delta t-\Delta h A_{\text {ave. }} .
$$

The above expression is suited for the analysis during the rainy period, which was discarded due to the larger number of unknown variables during those days (especially, due to the increase in the ungauged flow). Only dry period data (collected during days with positive potential seepage volume) were considered for the analysis. Data collected during a total of 92 dry days (April, May, September, and October of 2006) were analysed. For the dry period, equation (4) reduces to

$$
Q_{\text {out }} \Delta t=Q_{\text {in }} \Delta t-\Delta h A_{\text {ave. }} .
$$

When $Q_{\text {out }} \Delta t$ is zero, $Q_{\text {in }} \Delta t=\Delta h A_{\text {ave. }}$ (i.e., inflow entirely goes into storage plus evaporation; hence, there is no water for seepage). When $Q_{\text {out }} \Delta t>0$, it can be inferred that water is available for seepage. If $Q_{\text {out }} \Delta t<0$, it implies anomalous results, which can perhaps be attributed to the contribution of springs in the catchment area, which continues even during dry weather.

A set of calculations were performed for (1) the sums of upstream inflows and downstream discharges for both lakes, (2) seepage volumes of both channels (expressed as the percentage of the upstream and downstream flows), and (3) seepage volume within the pore spaces of the dam body. 
4.1.7. Seepage Discharge and Surface Flow Measurements from Karli Lake. The seepage water appeared at multiple new locations along segment 2 of the Karli spillway (see Figures 5(a) and 9(a)) starting on February 5, 2007, when the lake surface elevation was at $1335 \mathrm{~m}$ AMSL. Unusual rainfall in the month of March 2007 also accelerated the process of lake filling, as evident from the slope steepness at the end of the filling curve shown in Figure 16(a). Karli lake overtopped the spillway on March 31, 2007. Measurements of water at the new seepage points and from the overtopping flow could reveal information, possibly aiding in the assessment of surface erosion/piping through the dam body. Accordingly, discharge/flow rate measurements and water sampling were done at both of the newly developed seepage locations and later at two other points along the spillway: one near the end of segment 1 and a second one at the lowest elevation point along segment 2. The seepage locations, flow/discharge rates, and the suspended sediment concentration measurements from the water samples were analysed against the Karli inflow and RES2DINV resistivity model. The sediment concentrations were measured using Test Method A of the ASTM Standard [32].

4.1.8. Numerical Simulations for Seepage Analysis. The finite element-based SEEP/W module of GEOSLOPE software was used for seepage analyses of the Hattian Bala landslide dam. These analyses were performed under static loading conditions, including simulations for two distinct downstream boundary conditions (i.e., zero flux, and downstream head commensurate with the original channel bed, i.e., at $1 \backslash 100 \mathrm{~m} \mathrm{AMSL}$ ), and for the following pondage levels of the Karli lake:

(i) $1329 \mathrm{~m} \mathrm{AMSL}$, recorded during phase 1 of the field investigations

(ii) $1336 \mathrm{~m}$ AMSL, recorded during phase 2 of the field investigations

(iii) $1352 \mathrm{~m}$ AMSL, commensurate with maximum lake capacity and the highest bed elevation of the Karli spillway

The finite element model of the subsurface developed in SEEP/W was replicated from the pseudosection obtained from the RES2DINV resistivity program. The model consisted of 22,690 elements and 23,074 nodes. Different zones within this model were assigned $k$ values based on the calibrations performed during the laboratory investigations between $k, \rho$, and $\rho_{\mathrm{d}}$ values and comparing those with the RES2DINV pseudosection. Simulations were run for likely combinations of the boundary conditions. Effort was made to conceptualize various threshold combinations of conditions and parameters, which could generate instability in the dam. The SEEP/W model prepared for these simulations along with the permeability values assigned to various zones is shown in Figure 17. It can be noticed that the zone at the toe of the landslide dam (orange) was assigned a very low permeability value. This zone consisted mainly of boulderand cobble-sized particles in which longitudinal electrical resistivity surveys could not be extended in both phases of the investigations. The $234 \mathrm{~m}$ long transverse resistivity survey conducted with great difficulty at the $1114 \mathrm{~m}$ location in the phase 2 investigations indicated very high subsurface resistivity. The low permeability values were, thus, assigned to match with the calibration model mentioned above.

4.2. Results and Interpretations. The following collective interpretations were derived from the results and findings of the combination of the investigative methodologies employed by the authors to study the stability of this landslide dam.

4.2.1. Index Tests. The dam was a heterogeneous body of landslide debris mass comprising of materials ranging from boulders to clay-size particles. Figure 18 presents the formal grain size analysis and the USCS classification of the six samples of matrix material collected from the Karli spillway. On average, about $60 \%$ of the matrix material consisted of particles finer than the \#4 sieve $(4.75 \mathrm{~mm}), 50 \%$ finer than the \#10 sieve $(2.00 \mathrm{~mm}), 38 \%$ finer than the $\# 40$ sieve $(0.425 \mathrm{~mm})$, and $28 \%$ contribution of fines (clay and silt-sized particles). Examples of the variety of the coarser fragments of the debris material from different parts of the dam are also shown in Figure 19.

4.2.2. Erosion Potential. Results from the comparison of the grain size distribution curves with that of the Sherard failure envelope [29] (see Figure 18) indicated that the dam material was significantly susceptible to internal erosion due to the seepage forces. However, since the material in the subsurface was a random assemblage of coarse and fine fragments of the crushed source rock, piping could not develop or advance in its classical sense. Instead, it was expected to be a slow process, extended over months and possibly years.

The results from the "no erosion filter criterion" analyses: $D_{15} / D_{85}$ ratio [33] are summarized in Table 4 . Out of a total of 36, twelve results (4 samples separated at 5 different particle sizes) satisfied the criterion. All the other ratios did not fit in the criterion. The overall mean value of 20.26 was considerably beyond the acceptable range, implying that the material forming the dam body was nonresistant to internal erosion. Nevertheless, this criterion would best work in embankments where the transition zones from fine to coarse material are somewhat definable. Therefore, clear erosion patterns through this dam with inhomogeneous configuration, composition, and grain size could not be assessed with much precision.

Based on the data, it was expected that erosion would develop due to overtopping flow and retrogressively advance from the toe to the upstream until the crest of the dam would start to erode. Piping was also anticipated to develop and advance at a relatively slower but constant pace at multiple locations along the dam body. This was also validated from the results of the suspended sediment concentration measured on the water samples from the two seepage points mentioned in the previous section (those results are discussed in a later subsection). 


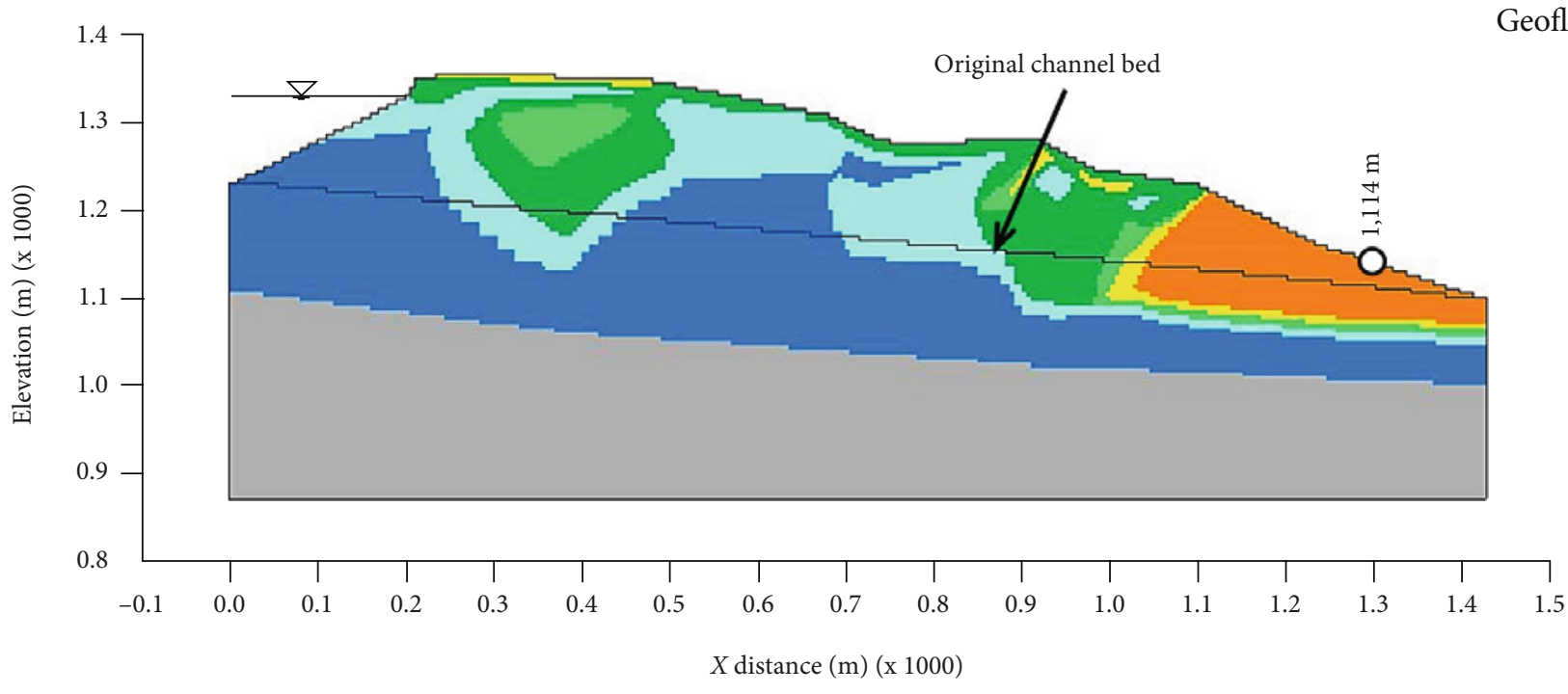

Permeability values assigned to zone

\begin{tabular}{|l|l}
\hline $6.3 \times 10^{-7} \mathrm{~m} / \mathrm{s}$ & $3.95 \times 10^{-9} \mathrm{~m} / \mathrm{s}$ \\
$1.5 \times 10^{-7} \mathrm{~m} / \mathrm{s}$ & $1.0 \times 10^{-9} \mathrm{~m} / \mathrm{s}$ \\
$8.4 \times 10^{-8} \mathrm{~m} / \mathrm{s}$ & $9.7 \times 10^{-10} \mathrm{~m} / \mathrm{s}$ \\
$9.8 \times 10^{-9} \mathrm{~m} / \mathrm{s}$ & \\
\hline
\end{tabular}

FIGURE 17: Finite element model used in SEEP/W for seepage analyses of the landslide dam section along the longitudinal survey line.

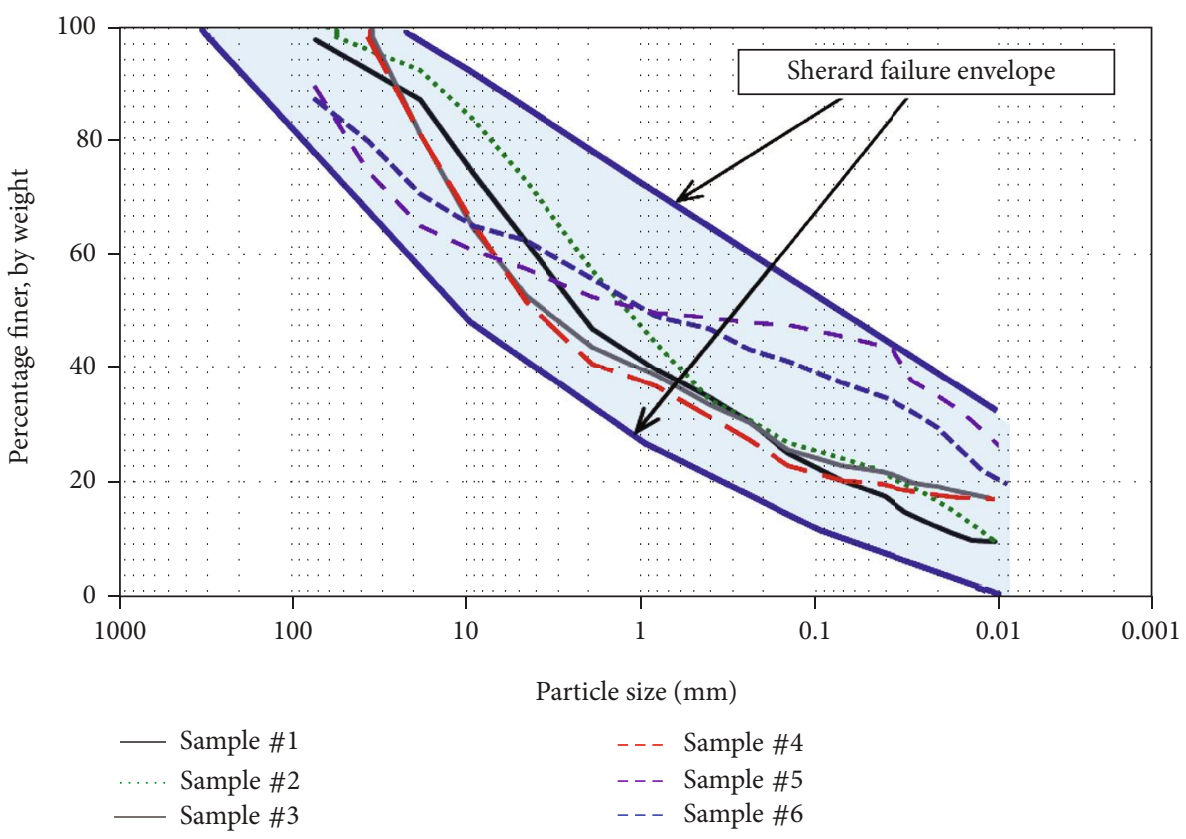

\begin{tabular}{|c|c|c|c|c|c|c|c|}
\hline \multirow{2}{*}{$\begin{array}{l}\text { Sample } \\
\text { no }\end{array}$} & \multicolumn{3}{|c|}{ Particle size distribution (\%) } & \multirow{2}{*}{$\begin{array}{l}\mathrm{LL} \\
(\%)\end{array}$} & \multirow{2}{*}{$\begin{array}{l}\text { PL } \\
(\%)\end{array}$} & \multirow{2}{*}{$\begin{array}{l}\text { PI } \\
(\%)\end{array}$} & \multirow[t]{2}{*}{ USCS } \\
\hline & Gravel & Sand & Silt/clay & & & & \\
\hline 1 & 37.7 & 42.5 & 19.8 & 19.8 & 16.0 & 3.8 & SM (d) \\
\hline 2 & 26.8 & 49.5 & 23.7 & 24.7 & 16.3 & 8.3 & SC \\
\hline 3 & 47.3 & 30.3 & 22.4 & 17.6 & 13.4 & 4.2 & GM-GC \\
\hline 4 & 48.3 & 31.9 & 19.8 & 18.8 & 16.1 & 2.7 & GM (d) \\
\hline 5 & 42.6 & 11.8 & 45.6 & 19.5 & 12.6 & 6.9 & GM-GC \\
\hline 6 & 37.4 & 25.4 & 37.2 & 20.2 & 13.4 & 6.8 & GM-GC \\
\hline
\end{tabular}

FIGURE 18: Grain size distribution curves, Atterberg limits, and the USCS classification of matrix samples from Karli spillway. 


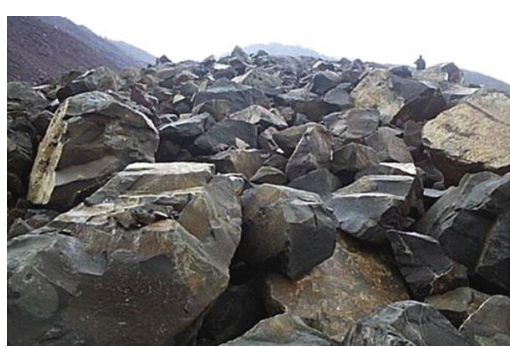

(a)

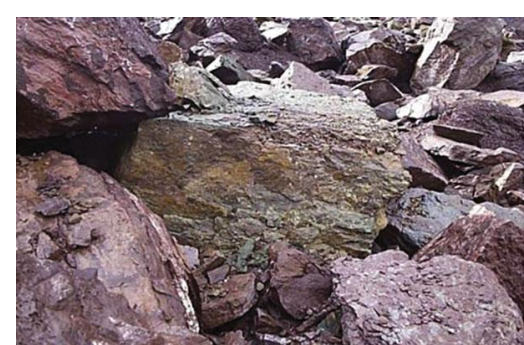

(b)

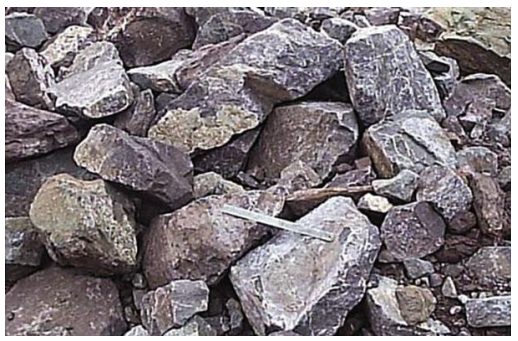

(c)

FIGURE 19: Examples of coarse materials from Hattian Bala landslide dam: (a) grey sandstone; (b) purple to reddish-brown mudstone (shale); (c) sandstone (used as a scale is a $12^{\prime \prime}$ stainless steel ruler).

TABLE 4: $D_{15} / D_{85}$ ratios for samples of the matrix material from the Hattian Bala landslide dam separated at selected particle sizes.

\begin{tabular}{|c|c|c|c|c|c|c|c|}
\hline \multirow{2}{*}{ Sample no. } & \multicolumn{6}{|c|}{ Particle size of separation (mm) } & \multirow{2}{*}{ Mean $D_{15} / D_{85}$} \\
\hline & 0.15 & 0.43 & 0.85 & 2.00 & 4.75 & 9.53 & \\
\hline 1 & 5.80 & 6.11 & 5.68 & 3.69 & 2.51 & 2.01 & 4.30 \\
\hline 2 & 10.21 & 4.02 & 2.71 & 2.58 & 2.53 & 2.42 & 4.08 \\
\hline 3 & 9.12 & 9.48 & 7.73 & 6.07 & 3.38 & 1.89 & 6.28 \\
\hline 4 & 14.69 & 9.47 & 7.29 & 6.29 & 2.77 & 1.69 & 7.03 \\
\hline 5 & 103.19 & 114.31 & 127.66 & 135.21 & 26.88 & 14.41 & 86.94 \\
\hline 6 & 21.10 & 15.53 & 13.10 & 9.02 & 9.81 & 9.16 & 12.95 \\
\hline Mean $D_{15} / D_{85}$ & 27.35 & 26.48 & 27.36 & 27.14 & 7.98 & 5.26 & 20.26 \\
\hline
\end{tabular}

4.2.3. Laboratory Calibration for Resistivity, Saturation, Permeability, and Density. The combined results of resistivity $(\rho)$ vs. dry density $\left(\rho_{\mathrm{d}}\right)$ and degree of saturation $(S)$ and permeability $(k)$ vs. $\rho_{\mathrm{d}}$ from a series of laboratory tests are shown in Figure 20. The overall $k$ of the dam was low, decreasing by about two orders of magnitude from $6.3 \times 10^{-7}$ to $4.0 \times$ $10^{-9} \mathrm{~m} / \mathrm{s}$ over the range of $\rho_{\mathrm{d}}$ that represented a natural state of the material within the dam body (i.e., 1520 to $2090 \mathrm{~kg} / \mathrm{m}^{3}$ ). The corresponding $\rho$ values calculated from the laboratory measurements were influenced by both $\rho_{\mathrm{d}}$ and $S$. The overall range of $\rho$ was found to be 37.9 to 218.3 ohm-m, decreasing for $\rho_{\mathrm{d}}$ as well as $S$. The decrease in $\rho$ with the increase in $\rho_{\mathrm{d}}$ was more pronounced for the samples tested in a drier state compared to those with higher degrees of saturation. The $\rho$ values of the samples tested at different $\rho_{\mathrm{d}}$ converged to an average value of $39.9 \mathrm{ohm}-\mathrm{m}$ for $S=$ $100 \%$.

The matrix material used in this testing was a mix of naturally crushed rock from their sources of limestone and mudstone (shale). The resistivity values obtained from this test series were, therefore, also compared with the typical range of resistivity values for sandstone: $10 \mathrm{ohm}-\mathrm{m}$ (wet) to $2500 \mathrm{ohm}-\mathrm{m}$ (dry) and shale: $25 \mathrm{ohm}-\mathrm{m}$ (wet) to 1500 ohm-m (dry) [20]. These results and analyses offered a fair assessment of the expected ranges of resistivity, permeability, degree of saturation, and density at the site, interpretation of the RES2DINV pseudosections of the surface from field resistivity data, and selection of permeability values for different zones in the SEEP/W analysis.

4.2.4. Subsurface Pseudosection from Field Electrical Resistivity Surveys. The subsurface 2D pseudosections resulting from the field electrical resistivity survey data of the two phases and their inverse modelling in RES2DINV are shown in Figure 21. It may be noted that the resistivity values shown are the true values obtained from "inversion" of the resistivity values calculated directly from the measured resistance data in the field. Due to the overlapping range of typical resistivity values of shale and sandstone in their wet to dry states, it was 


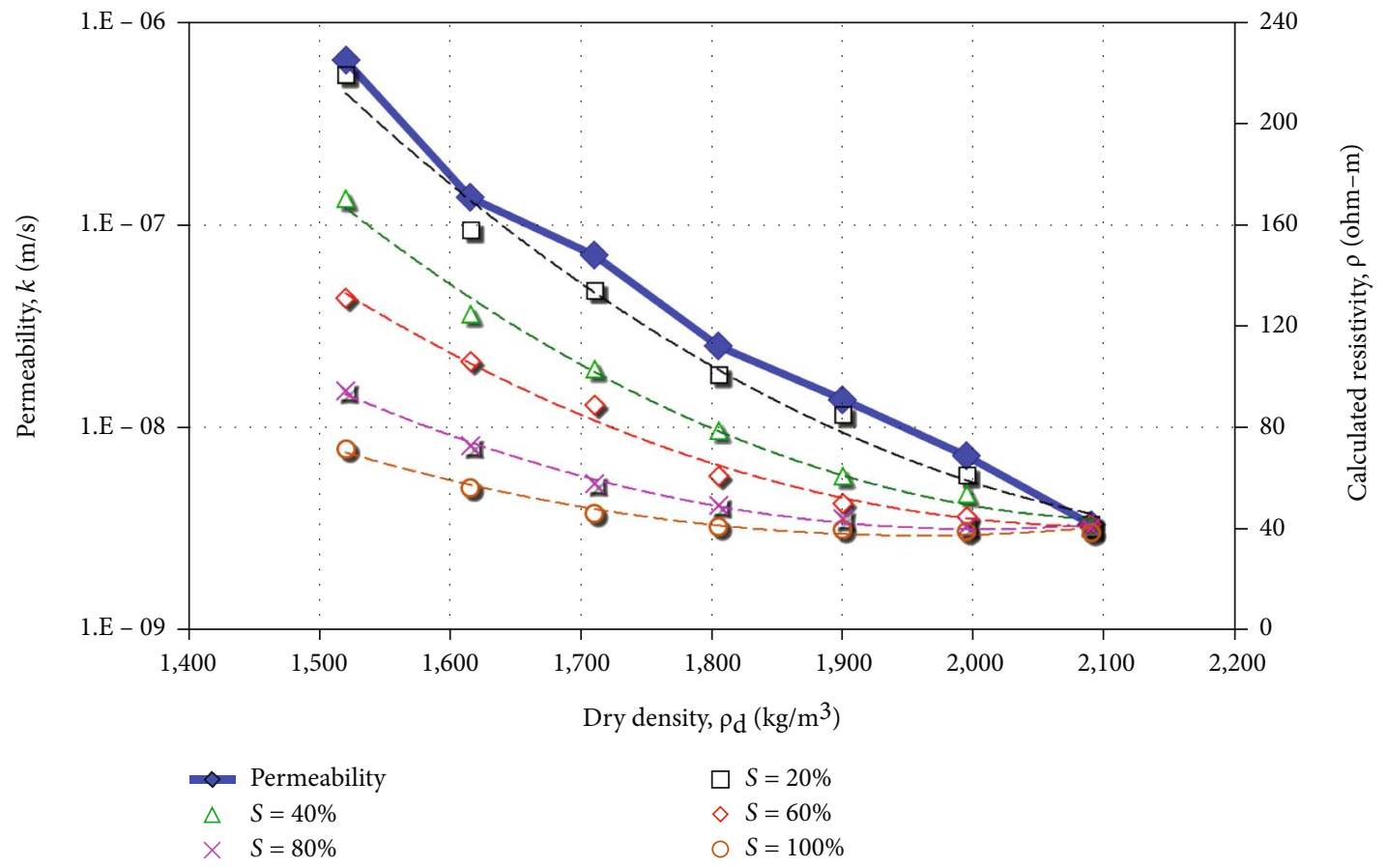

Figure 20: Results of laboratory tests on samples of matrix material from the Hattian Bala landslide dam, including permeability tests at different densities (plotted on a semilogarithmic scale on the primary vertical axis), and resistivity at different densities and degrees of saturation (on the arithmetic scale on the secondary vertical axes).

not possible to associate different zones to one type or the other source material. Thus, it was prudent to assume that the entire dam consisted of a mix of crushed sandstone and shale and the resistivity values in different zones were a reasonable representation of their respective densities, degrees of saturation, and permeability. A concise summary of the interpretations derived from these profiles is given below:

(i) Phase 1 Longitudinal Survey. This model indicated two low resistivity (interpreted as highly saturated) zones in the dam body. The limits of the first zone adjacent to the upstream toe of the dam were compatible with the Karli lake surface elevation of $1329 \mathrm{~m}$ AMSL, noted at that time. From the depth perspective, this zone extended below the original Karli channel bed level, whereas its longitudinal dimension was about $100 \mathrm{~m}$. The second zone extended horizontally from approximately $260 \mathrm{~m}$ up to $685 \mathrm{~m}$ from the upstream edge of the spillway (freeboard edge), and its depth varied from near the surface to below the original Karli channel bed. A part of this zone also relates to the lowest point along segment 2 of the spillway where seepage water reappeared on the surface at two locations in February 2007. A medium resistivity (interpreted as intermediate density and permeability) zone was sandwiched between the two low resistivity saturated zones, which could hinder the development of smooth flow paths and thus impede the flow of water. A zone characterized by extremely high resistivity values (representing very high density and low permeability) was found in the subsurface towards the end of the survey line extending horizontally from $780 \mathrm{~m}$ to $894 \mathrm{~m}$ from the upstream edge of the spillway. The resistivity values in this zone increased from about $650 \mathrm{ohm}-\mathrm{m}$ at the spillway bed to more than $6000 \mathrm{ohm}-\mathrm{m}$ at $150 \mathrm{~m}$ below that bed. Such high resistivity values could be attributed to the existence of very dense material and the possibility that the seepage fronts had not advanced through those layers by that time.

(ii) Phase 1 Transverse Resistivity Surveys. The four transverse resistivity profiles of phase 1 are shown in Figure 21. As mentioned above, these additional surveys were conducted to verify the profile obtained from the longitudinal survey. Since the longitudinal survey was conducted along the spillway bed, the main portions of interest from the transverse survey profiles were those below their lowest crest elevations (these elevations correspond to the spillway bed). The maximum depths of investigations for the transverse resistivity surveys at $22 \mathrm{~m}, 124 \mathrm{~m}$, $237 \mathrm{~m}$, and $574 \mathrm{~m}$ extended vertically up to $20 \mathrm{~m}$, $26 \mathrm{~m}, 28 \mathrm{~m}$, and $16 \mathrm{~m}$ below the spillway bed, respectively. The resistivity values of the $22 \mathrm{~m}$ transverse survey profile indicated an increase from $175 \mathrm{ohm}$ $\mathrm{m}$ at the spillway bed to $800 \mathrm{ohm}-\mathrm{m}$ at $20 \mathrm{~m}$ depth, whereas those of the $124 \mathrm{~m}$ transverse survey profile increased from $350 \mathrm{ohm}-\mathrm{m}$ at the spill bed to about $1000 \mathrm{ohm}-\mathrm{m}$ at $12 \mathrm{~m}$ depth and then decreased down to about $150 \mathrm{ohm}-\mathrm{m}$ at $26 \mathrm{~m}$. For the third transverse resistivity survey at $237 \mathrm{~m}$, the values varied between 95 ohm-m and about 1000 ohm-m 

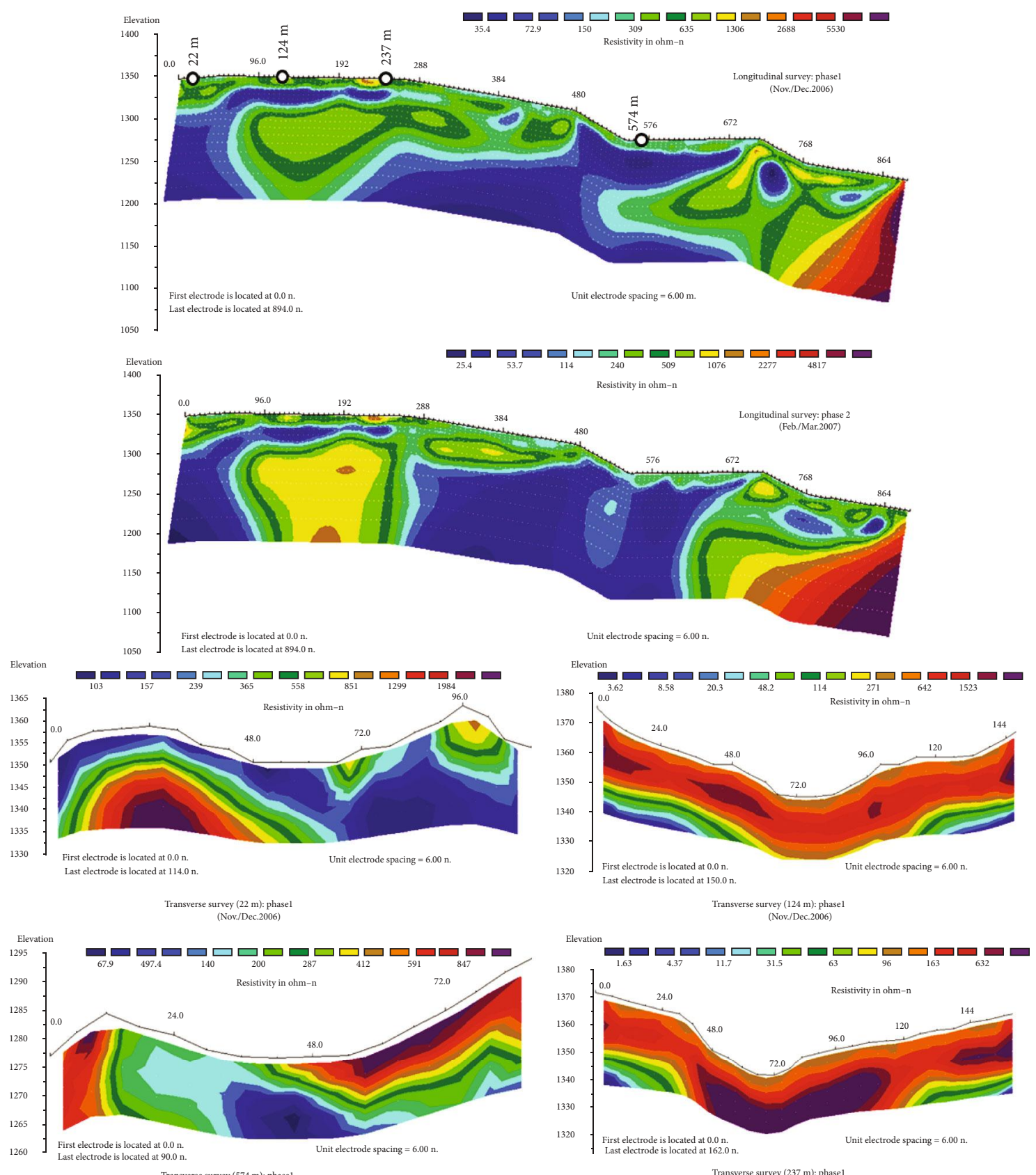
Transverse survey (574 m): phase

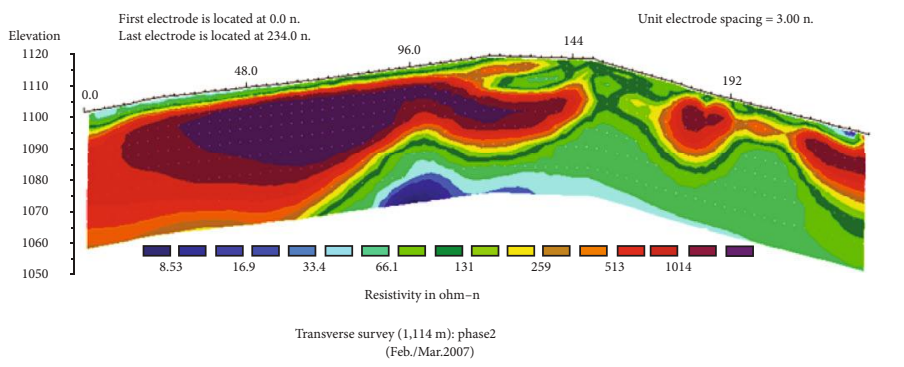

FIGURE 21: Longitudinal and transverse resistivity profiles of Karli spillway from RES2DINV modelling integrating data from two phases on field investigations. 
within the $28 \mathrm{~m}$ depth zone, whereas for the transverse survey at $574 \mathrm{~m}$, the value decreased from about $300 \mathrm{ohm}-\mathrm{m}$ at the spillway bed to about 60 $\mathrm{ohm}-\mathrm{m}$ at $16 \mathrm{~m}$ depth. Interestingly, these resistivity values obtained from the transverse profiles are in general agreement with the values of the longitudinal profile of that phase, thus validating the subsurface inversion model and the interpreted conditions.

(iii) Phase 2 Longitudinal Survey. The time-lapse water infiltration longitudinal resistivity surveys, conducted during the phase 2 field investigations in February/March 2007, exhibited a general increase in the extents of low resistivity (high saturation) zones. This increase could be attributed to (1) rise in the Karli lake surface elevation by $7 \mathrm{~m}$ from December 2006 to March 2007 and (2) excessive rainfall $(401.5 \mathrm{~mm}$ total) during a time-lapse of three months between the two phases of the surveys (Surface Water Hydrology Project, Water and Power Development Authority Pakistan, personal communication, unpublished data, March 2007). The surface runoff from the rainwater accumulated and percolated into the dam body, particularly at the lowest point along segment 2 of the spillway. The decrease in the resistivity values was maximum in the subsurface below that location.

(iv) Phase 2 Transverse Resistivity Survey. The only transverse resistivity survey of phase 2 was performed near the toe end of the dam (at $1114 \mathrm{~m}$ from the upstream end of the spillway). Accordingly, this survey line was located $220 \mathrm{~m}$ towards the downstream side from the end point of the longitudinal survey line of the two phases (also see Figure 12). Because of that distance, the results from this survey could not be used to validate directly any part of the longitudinal profile. However, it was conducted to investigate whether the extremely high resistivity zone observed near the end of the two longitudinal surveys further extended towards the downstream toe end. The profile developed from this $234 \mathrm{~m}$ long survey extended $41 \mathrm{~m}$ deep below the surface (see Figure 21). The reduced electrode spacing provided higher resolution. The results indicated variation of the resistivity values between $150 \mathrm{ohm}-\mathrm{m}$ and $1500 \mathrm{ohm}-\mathrm{m}$ within the top $25 \mathrm{~m}$. The values were much lower than those observed in the end segment of the longitudinal surveys of both phases. It was interpreted that the extremely high resistivity zone found below the $780 \mathrm{~m}$ to $894 \mathrm{~m}$ stretch of the longitudinal survey gradually decreased in values towards the toe end of the dam. In the lower $15 \mathrm{~m}$ of the profile, the resistivity values decreased to less than $20 \mathrm{ohm}-\mathrm{m}$. This low resistivity (interpreted as a highly saturated zone) corresponds to depths below the original channel bed. This particular observation hinted to a possible connection with the second low-resistivity saturated zone of the longitudinal surveys through the deeper strata.

4.2.5. Hydrological Database Analysis. The observations noted from the graphical presentation of the hydrological data and the calculations performed using the methodology explained in the previous section are summarized below:

(i) The surface elevation of the Karli lake constantly rose up to its maximum at $1352 \mathrm{~m}$ AMSL, when its water overtopped through the spillway on March 31, 2007

(ii) The Tung lake surface elevation fluctuated between $1215.71 \mathrm{~m}$ and $1223.10 \mathrm{~m}$ AMSL (in sync with periodic rainfall) for the duration of the data collection period. Comparing these levels with the Tung spillway elevation at $1223.10 \mathrm{~m}$ AMSL gave a clear indication of seepage resulting from internal erosion from that part of the landslide dam

(iii) The upstream inflows of the two channels and the downstream discharge for the period under consideration fluctuated between the following limits:
(a) Karli upstream: 0.257 and $2.897 \mathrm{~m}^{3} / \mathrm{s}$
(b) Tang upstream: 0.213 and $2.806 \mathrm{~m}^{3} / \mathrm{s}$
(c) Downstream: 0.370 and $2.870 \mathrm{~m}^{3} / \mathrm{s}$

(iv) During the dry spells (April, May, September, and October of 2006), the inflow from both lakes showed a decreasing trend

(v) The sum of the upstream inflow from both channels was distinctly higher (i.e., 1.47 times, on average) than the net downstream discharge (i.e., $Q_{\text {in,combined }}>Q_{\text {out,combined }}$ ) over the duration of the data collection period

(vi) The net downstream discharge was more than the net upstream inflow of the Tung channel for $95.44 \%$ of the data duration, except for the dates characterized by heavy rainfall $(34 \mathrm{~mm}$ to $63 \mathrm{~mm}$ )

(vii) The two previous observations combined were indicative of one of the two possibilities: (1) water from the Karli lake was already contributing to the downstream discharge via seepage through the dam body or (2) ungauged hydrological features (i.e., nonperennial small channels and springs between the toe of the dam and the downstream measurement gauge) periodically added to the seepage from the Tung lake

(viii) The actual daily increase in the Karli lake volume $\left(Q_{\text {vol.cont. }}\right)$, calculated using the polynomial expression of equation (2), when compared with those calculated as the total daily inflows from Karli channel $\left(Q_{\text {vol.dis. }}\right)$, indicated that $Q_{\text {vol.cont. }}>Q_{\text {vol.dis. }}$ for the rainy days and few of the following days. However, the dry months (April, May, September, and October of 2006) showed an opposite trend, i.e., $Q_{\text {vol.cont. }}<Q_{\text {vol.dis. }}$ 
TABLE 5: Overtopping flow/seepage discharge and sediment concentration measurements.

\begin{tabular}{|c|c|c|c|c|c|c|}
\hline \multirow[b]{2}{*}{$\begin{array}{l}\text { Discharge } \\
\text { location }\end{array}$} & \multicolumn{3}{|c|}{ February 26, 2007} & \multicolumn{3}{|c|}{ April 2, 2007} \\
\hline & $\begin{array}{c}\text { Discharge } \\
\left(\mathrm{m}^{3} / \mathrm{s}\right)\end{array}$ & $\begin{array}{c}\text { Sediment } \\
\text { concentration }(\mathrm{mg} / \mathrm{l})\end{array}$ & $\begin{array}{l}\text { Sediments smaller than } \\
\text { (sieve size) }\end{array}$ & $\begin{array}{c}\text { Discharge } \\
\left(\mathrm{m}^{3} / \mathrm{s}\right)\end{array}$ & $\begin{array}{c}\text { Sediment } \\
\text { concentration }(\mathrm{mg} / \mathrm{l})\end{array}$ & $\begin{array}{l}\text { Sediments smaller than } \\
\text { (sieve size) }\end{array}$ \\
\hline No. 1 & 0.085 & 12,000 & $\# 40$ & 0.126 & 17,500 & \# 30 \\
\hline No. 2 & 0.115 & 23,450 & \# 20 & 0.234 & 29,650 & \# 16 \\
\hline No. 3 & - & - & - & 1.07 & 118,000 & $\# 10$ \\
\hline No. 4 & - & - & - & 0.86 & 106,500 & $\# 10$ \\
\hline
\end{tabular}

(ix) The potential seepage volume $\left(Q_{\text {out }} \Delta t\right)$ calculations from equations (2)-(5) over a period of 92 dry days from the data of the two channels yielded the following results:

(a) Total $Q_{\text {in }} \Delta t$ for 92 days $=10.8$ million $\mathrm{m}^{3}$

(b) Total downstream discharge for 92 days $=7.8$ million $\mathrm{m}^{3}$

(c) $Q_{\text {out }} \Delta t$ for 92 days $=7.3$ million $\mathrm{m}^{3} \quad(67.6 \%$ of $Q_{\text {in }} \Delta t$ and $93.4 \%$ of the downstream discharge)

(d) $Q_{\text {out }} \Delta t$ trapped within the dam body $=-0.5$ million $\mathrm{m}^{3}$

(x) One-third of $Q_{\text {in }} \Delta t$ from the two lakes was lost in seepage and evaporation, combined. The seepage part of the loss was occurring (1) below the Tung spillway, (2) due to water entrapped in the pore spaces of the main dam body (under the Karli spillway), and (3) from infiltration/seepage along the perimeter of the Karli lake surface with water touching fresh and relatively dryer strata for each daily rise in the level

(xi) The apparently unrealistic negative value of the seepage volume trapped within the dam body could also be attributed to contributions to the downstream discharge by the ungauged hydrological features mentioned above

(xii) The final breach of the two lakes, which occurred at a later timeframe (February and July of 2010), can be attributed to the slaking of the remnants of the coarse fragments of shale present within the dam body from the seepage and surface overflow, as reported by Kiyota et al. [14]

(xiii) The daily precipitation recorded for the duration of the data was noted to be less than the historical average shown in Figure 16(b) (except for November and December of 2006). Any future rainfall at or higher than the average could result in an increased rate of surface erosion as well as seepage forces due to the runoff from the adjoining slopes/catchment and the rainwater percolating into the dam surface

4.2.6. Seepage Discharge and Surface Flow Measurements from Karli Lake. The results of the field measurements, sam- pling, and laboratory testing from the surface water flow and seepage discharge at four locations along Karli spillway are summarized in Table 5. The results indicated the following:

(i) The discharge at the seepage points increased with time; their sediment concentration in the seepage flow was notable, which was a clear sign of internal erosion

(ii) The sediment concentration increased over the measurement period, and so did the sediment size, an indication of the evolution of internal erosion

(iii) The discharge measurements recorded from the overtopping flow at location 3 were lower than the upstream inflow from the Karli channel. Similarly, the discharge at location 4 along the spillway was lower than that at location 3. From this observation, it was deduced that a significant quantity of water from the streamflow was percolating into the dam body, resulting in an increase in the degree of saturation, and seepage pressures

(iv) The sediment concentration in the surface flow was significantly higher than that from the seepage discharge. The largest grain size being eroded due to surface flow was also larger than that from the seepage discharge. This assessment validated the interpretation of possible retrogressive erosion over time, which was derived from the erosion potential assessment detailed above

(v) These interpretations were based on the limited set of the readings tabulated above. Conclusive findings warranted continuous measurements of seepage and surface flow trends, together with upstream and downstream discharges and the lake elevations

4.2.7. Computer-Simulated Seepage Analysis. While numerical simulations and analysis for the seepage of water from Karli lake were performed in the SEEP/W program for three different lake elevations (1329 m AMSL in December 2006, $1336 \mathrm{~m}$ AMSL in early March 2007, and the maximum lake capacity of $1352 \mathrm{~m}$ AMSL on March 31, 2007), only selected results at the final elevation are presented in Figure 22. For the modelled scenarios, the phreatic surface, the flow lines, and the velocity vectors, shown in Figure 22, provided a decent understanding of the seepage flow patterns below the Karli spillway when reaching a steady-state condition. These assessments helped in relating the overall model to 


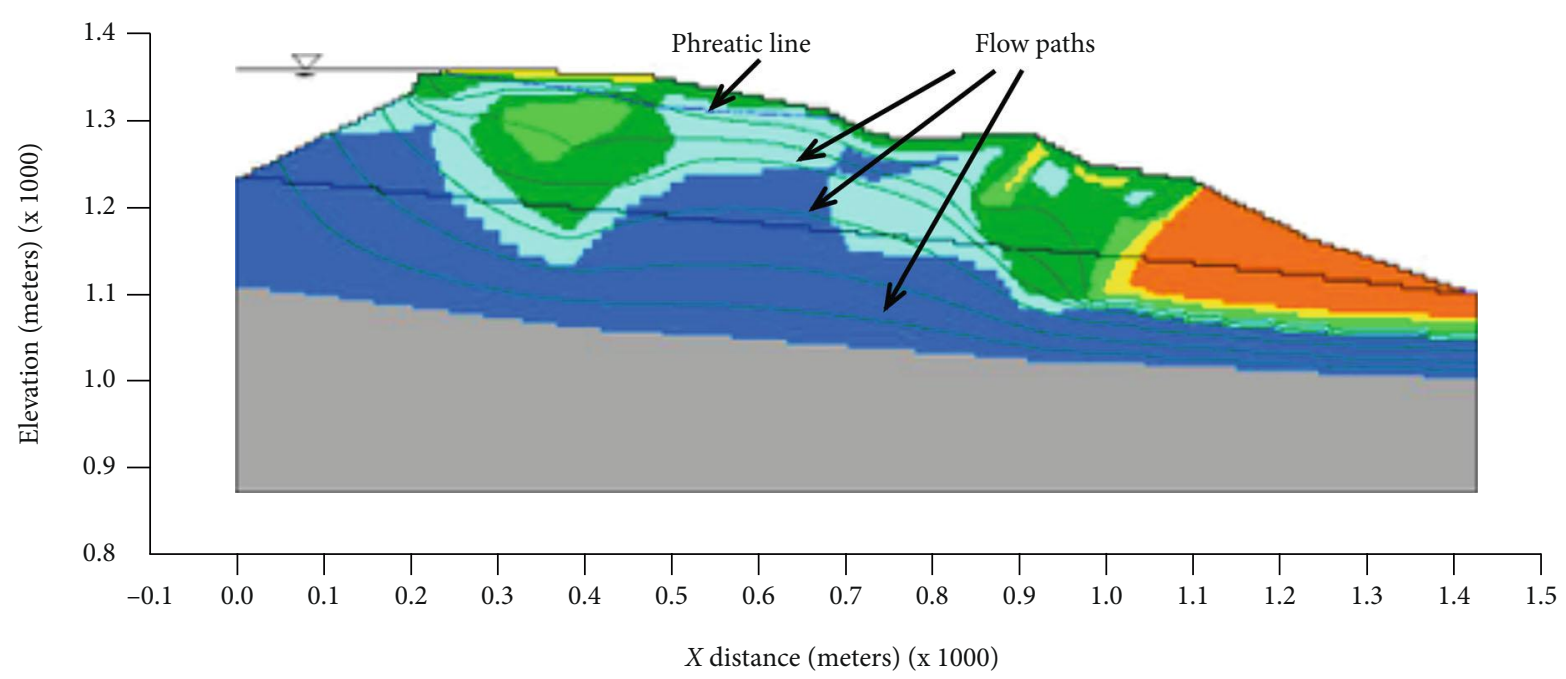

(a)

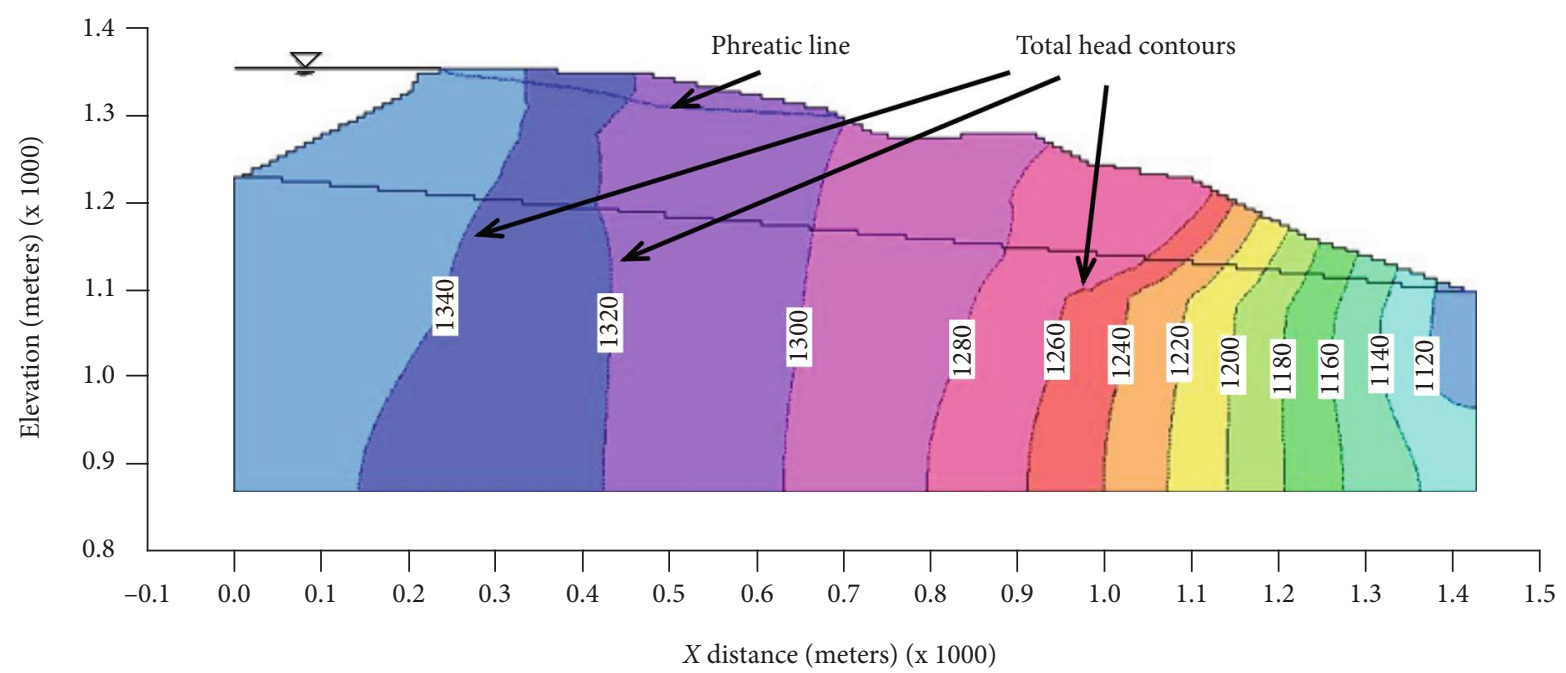

(b)

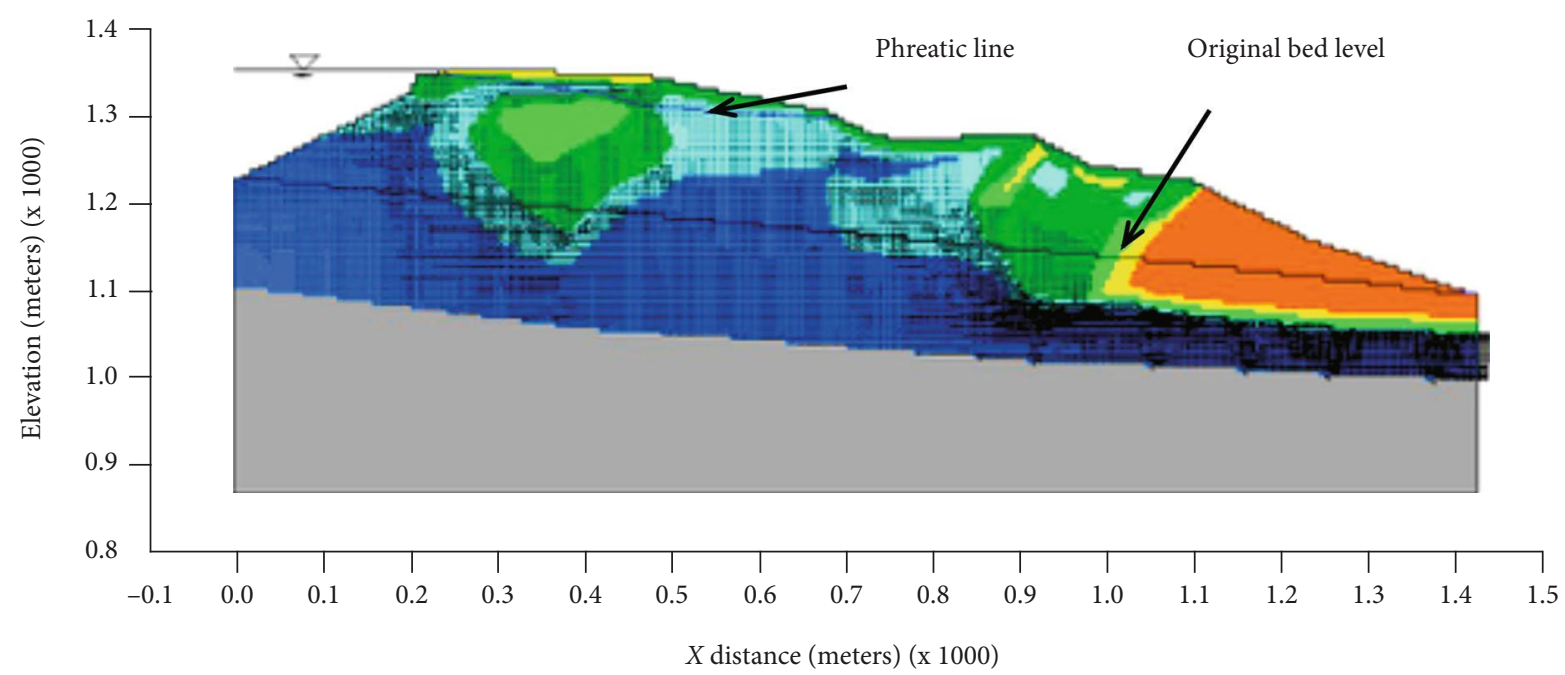

(c)

Figure 22: Continued. 


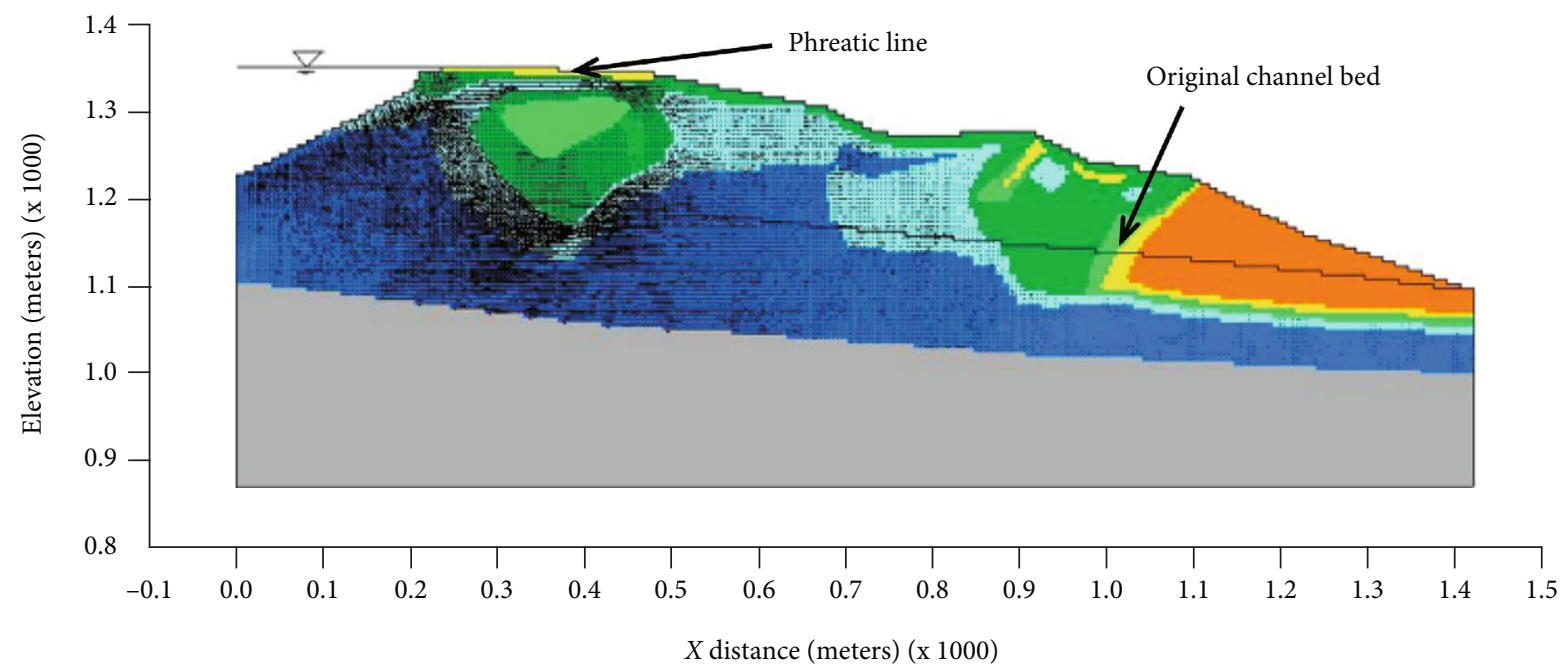

(d)

FIGURE 22: SEEP/W simulation results for Karli spillway (lake level at $1352 \mathrm{~m} \mathrm{AMSL):} \mathrm{(a-c)} \mathrm{flow} \mathrm{paths,} \mathrm{total} \mathrm{head} \mathrm{contours,} \mathrm{and} \mathrm{velocity}$ vectors, respectively, for the head at the downstream toe end equal to the original channel bed, and (d) velocity vectors for zero flux at the downstream toe end.

the existing seepage locations and in estimating the future possible locations along the spillway. The following were explicated from the results:

(i) In the simulations modelled for three pondage levels with zero flux condition at the downstream toe end, the phreatic line daylights on the spillway surface very close to the upstream face of the dam (see Figure 22(d)). However, no such signs were observed during any phase of the site investigations or visits. It implied the possible use of incorrect downstream boundary conditions and/or a transient state of the actual seepage under the spillway in contrast to the steady-state model for which the analyses were run

(ii) The phreatic line, generated in the simulations with the downstream head at the same elevation as the original channel bed, daylights on the spillway surface near the lowest elevation point of its segment 2 (see Figure 22). As mentioned earlier, the two seepage points, initiated in February 2007, were located adjacent to this spot. Thus, this combination of boundary conditions and simulation seemed to be closer to the actual site conditions

(iii) The concentration of the flow paths (see Figure 22(a)) and the velocity vectors (see Figure 22(c)) lower in elevation than the original channel bed near the toe of the dam suggest that seepage in the toe zone of the dam would be unlikely, and therefore, the possibility of internal erosion/piping due to seepage forces would not be possible in that area (note that erosion in that zone due to surface flow was not analysed in this simulation). Nevertheless, keeping in view the difficulty in conducting the resistivity survey and the ensuing RES2DINV modelling of the subsurface in the downstream toe segment, cautious interpretations from the simulation results are needed, particularly for that zone of the dam

(iv) The flow paths and the velocity vectors in all modelling and simulation cases indicate that a significant quantity of seepage water entering the dam from its upstream face would surge upwards towards the surface along segment 2 of the spillway after bypassing the first high resistivity (high density and low permeability) zone. The seepage locations 1 and 2 could be conveniently related to these results

(v) The total head contours shown in Figure 22(b) indicate that the head loss over the initial twothirds of the dam width was less than that in the remaining one-third toe segment of the dam. These results evidenced an uneven distribution of seepage forces in different parts of the dam, which would possibly result in the appearance of seepage water back to the surface at multiple points along the uneven topography of the dam

(vi) To synopsize, a multidirectional approach was adopted for investigating an unconventional geotechnical and geological problem. Because of the inherent complexity and the many ungauged variables involved in the problem, a considerable degree of engineering judgement and observations had to be relied upon to reach reasonable qualitative results. The techniques employed for the analysis were more objective and based on newer data compared to those of the other preliminary studies conducted for this site 
(vii) Under normal static conditions, the chance of a catastrophic failure was regarded as a rare possibility. Progressive failure due to internal erosion of fines as well as scouring at the surface and subsequent creep settlements were concluded to be part of the most likely scenario to develop over an extended duration. It was anticipated that an earthquake of high intensity, a sudden increase in the inflow due to excessive precipitation or cloud burst, or a large-scale landslide from the adjoining ridges into the Karli lake were the possible dynamic conditions that could significantly change the scenario

(viii) The hydrogeological immaturity of the dam was the main factor that continued to hinder any better assessment of the time needed for total washing out of fines and/or final development of the steady-state conditions. The findings and interpretations of this study were conveyed to the Engineering in Chiefs Task Force in May 2007 along with the recommendation for continuation of the hydrological data monitoring system by the local authorities, together with periodic site visits/surveys to observe seepage and distress points along and besides the Karli spillway. Much of what happened at this site, as covered in the chronology of the events in an earlier section, was consistent with the interpretations from the authors' study

\section{Summary of the Lessons}

5.1. Observational Method. All landslide dams are characterized by rapid formation and deposition of a complex configuration and composition of geomaterials in the valley floor that are hydrogeologically young and pose a permanent threat to the downstream population and infrastructure due to the possibility of their failure. The fact that a predominant majority of them are known to have failed in the past mostly due to seepage-induced internal or surface erosion, and slope failure caused by the imbalance in the state of equilibrium generated by those seepage forces, calls for a need of their stability assessment. Determination of the condition of stability at any time after their formation or prediction of the period in which their failure would become imminent is extremely difficult. A certain set of investigations applied to one case may end up being mostly irrelevant to another due to the inherent uniqueness at each site, including the distinct dimensional, geological, topographical, and hydrological settings. The evolving scenarios would always depend on a variety of known or measureable variables and also with limitations imposed by some unknown and/or ungauged ones. This entails a substantial degree of reliance on engineering judgement and continuous monitoring.

Indeed, the landslide dams are excellent examples of the application of Terzaghi's Observational Method [34], which suggests initial computations for the working hypotheses based on preliminary data, followed by their confirmation or modification during the project implementation through continuous monitoring and data collection. The hypotheses considered must include the most probable condition as well as the most unfavourable conceivable deviations. Vigilance is at the heart of this "learn as you go" approach.

5.2. Applicable Investigative Tools and Stages of Investigations. Despite the quandary mentioned above, the overall pattern of faring with these natural geomorphological features may possibly require most of the following:

(i) Site visit/reconnaissance to get the fundamental understanding of the scale of the problem and the overall site

(ii) The study of existing topographical, geological, hydrological, and seismic records of the site and the catchment area

(iii) A fresh topographical survey of the dam area to quantify the volume of the debris material and their thickness and slopes at cardinal points aligned with the original valley floor (or along the most likely alignment of the overtopping flow)

(iv) A higher resolution topographic survey of the catchment area to quantify the impounded volume of water corresponding to different lake levels and that of the maximum capacity

(v) The elaboration of a fresh hazard zonation map, especially including identification of the critical landslide slopes prone to failure in the catchment area

(vi) Bulk sampling of the coarse and fine fragments of the debris material

(vii) Field investigations mainly including the noninvasive geophysical methods/tools

(viii) Laboratory testing, including the grain size analysis, permeability assessment at different densities, erosion and slaking potential, and in situ and reduced density, strength, and stiffness due to the effects of sustained exposure to seepage water, and calibrations for field data including geophysical measurements (if employed)

(ix) A system of continuous monitoring including the inflows and outflows for the dam and the lake elevations, suspended sediment concentration in the seepage and the overtopping flow waters, and distresses and deformations along critical locations using DGPS systems

(x) Numerical modelling for seepage and deformation analyses based on the field measurements and calibrations from the laboratory tests

(xi) Dam break analysis using downstream topography and numerical modelling

(xii) Preparing early warning and evacuation systems and rehearsals for the downstream population

5.3. Need for an Updated Central Database. The Hattian Bala landslide dam has been added to the inventory of those limited cases that lasted for more than one year. The fact that its 
failure, more than four years after formation, which was caused by excessive rainfall, is in agreement with the findings reported by Costa and Schuster [1] for previous failure cases. This specific case also attracted wide national and international attention because of the intensity of the earthquake that triggered the landslide and the overall catastrophic damage inflicted in that region. Both of these factors combined provided the required interest, reaction time, and resources to evaluate the problem and implement the mitigation measures. Other cases may not have the same latitude, requiring expeditious actions and with the constraint of even less data available (i.e., more unknown and/or ungauged variables), especially if the downstream population and/or infrastructure is at high risk. Full-scale mitigation work may not be an option due to the time and/or resource constraints. Therefore, employment of only selected investigative tools and steps from the above comprehensive list may be the best option. Availability of a central database of comprehensive case histories (from inception to failure or to stability) of the worldwide landslide dams, a summarized set of information from each case, and the overall comparative analysis will be helpful in handling future events of landslide dams.

5.4. Noninvasive Geophysical Methods. The invasive type of field investigation methods is not suited for this category of geotechnical problems as those methods provide information very specifically related to the point of investigation. Since the composition and configuration of landslide dams can be highly complex and heterogeneous, selective nonconventional tools like the noninvasive geophysical methods may be the only practical solution in the majority of cases. Geophysical methods cover large areas (vertical and lateral extents), they are expedient and less expensive, and they assess characteristics at small strain (i.e., true representation of elastic properties). However, since they develop a general picture instead of precise information (i.e., they provide qualitative results instead of quantitative), their interpretations require considerable prior experience and knowledge. In addition, laboratory calibrations of the measurements on the samples from the site are also warranted.

5.5. Numerical Simulations. Numerical modelling and computer simulations via reliable software can be very helpful in predicting the seepage and deformation of landslide dams. However, the model developed for this purpose, founded on data obtained from the use of geophysical or other investigation tools, must be a good representation of the subsurface strata and composition, and the values of the variables assigned in that model must be based on high-quality laboratory calibrations.

5.6. Hydrological Model. The hydrological database model presented in this paper for estimating the potential seepage volume can be refined for future applications by accounting for evaporation losses during the dry days, provided that temperature measurements are taken at or close to the site. Similarly, the model for the rainy days can also be developed by incorporating surface runoff data and contributions of perennial and nonperennial channels and springs. Accord- ingly, the authorities and investigators dealing with the analysis of the stability and mitigation of the landslide dams should strive to acquire that information during their data collection phase. Furthermore, the potential seepage volume cannot be estimated reliably until the lake has filled to its capacity or a reasonable pore water pressure equilibrium has been reached within the dam. This entails that the application of this proposed model would require continuous and extended monitoring of the hydrological data.

5.7. Collaborative Investigations. Because of the diverse nature of the variables involved in these problems, a collaborative cross-disciplinary approach of investigations and analysis is needed. Accordingly, knowledge and experience from geology, hydrology, seismology, meteorology, and geotechnical engineering has to be combined towards a cogent solution to such problems. While the application and combination of most of the above-mentioned fields were illustrated in the Hattian Bala case study, the field of seismology is also relevant in view of possible slope failures in the catchment area of the impounded lake due to an earthquake. A sudden slope failure due to a seismic event can generate a tsunami wave in the lake that may result in the dam break.

5.8. Qualitative versus Quantitative Findings. Precise prediction of the rate and progress of internal erosion and scouring and the resulting creep deformations is very difficult due to the extreme heterogeneity of the material within the overall dimensions of the landslide dams. Therefore, the combination of observational methods together with monitoring, vigilance, and early warning systems should be integral to any landslide dam project.

\section{Data Availability}

The data that support the findings of this study are available from the corresponding author upon reasonable request.

\section{Conflicts of Interest}

The authors declare that there is no conflict of interest regarding the publication of this paper.

\section{Acknowledgments}

The content presented in this paper was partly made possible due to the support and assistance of faculty and staff at the National Institute of Transportation of the National University of Sciences and Technology, Pakistan. The authors are particularly grateful to Dr. Nasrullah Abeer of the Engineering-inChief s Branch of Pakistan Army, who generously provided a significant share of the data used in this study.

\section{References}

[1] J. E. Costa and R. L. Schuster, "Documented historical landslide dams from around the world," U.S. Geological Survey Open-File Report no. 91-239, U.S. Geological Survey, 1991. 
[2] R. L. Schuster, "Landslide dams - a worldwide phenomenon," in Proceedings of the Annual Symposium of the Japanese Landslide Society, pp. 1-23, Osaka, 1993.

[3] O. Korup, "Recent research on landslide dams - a literature review with special attention to New Zealand," Progress in Physical Geography, vol. 26, no. 2, pp. 206-235, 2002.

[4] W. O. Engemoen, "Assessing the risk of a seepage-related dam failure by means of failure mode identification, risk analysis, and monitoring practices," in Proceedings of the Research Workshop on Seepage Through Embankment Dams, Denver, Colorado, 2000.

[5] R. P. Denlinger, D. R. H. O'Connell, and M. Jones, Summary of preliminary $2 \mathrm{D}$ inundation modeling for three Hattian landslide dam breach scenarios, Open-File Report no. 2006-1094, A joint project of the U.S. Geological Survey and the U.S. Department of Interior, Bureau of Reclamation, 2006.

[6] Asian Development Bank (ADB) and World Bank, Pakistan -2005 earthquake preliminary damage and needs assessment (English), Report no. 34407, World Bank Group, Washington, D.C, 2005, http://documents.worldbank.org/curated/en/ $710481468284380489 /$ Pakistan-2005-earthquakepreliminary-damage-and-needs-assessment.

[7] Google Earth, "Satellite image," 2005, http://www.earth.google .com.htm.

[8] K. Hoeg, O. A. Hoydal, V. Kveldsvik, O. Kjekstad, R. OlssonAll et al., The Pakistan October earthquake report from NGI's second mission, 4-11 January 2006, Hattian Bala landslide dam, Norwegian Geotechnical Institute, 2006.

[9] National Engineering Services Pakistan, (Private) Limited (NESPAK), and Geological Survey of Pakistan, Potential hazard of landsliding and mitigation measures at Hattian Bala and other earthquake hit areas, study of Hattian Bala landslide, A Joint Investigation Report, National Engineering Services Pakistan, 2006.

[10] A. Sattar, K. Konagai, T. Kiyota, T. Ikeda, and J. Johansson, "Measurement of debris mass changes and assessment of the dam-break flood potential of earthquake-triggered Hattian landslide dam," Landslides, vol. 8, no. 2, pp. 171-182, 2011.

[11] K. Konagai and A. Sattar, "Partial breaching of Hattian Bala landslide dam formed in the 8th October 2005 Kashmir earthquake, Pakistan," Landslides, vol. 9, no. 1, pp. 1-11, 2012.

[12] N. Abeer, Landsliding and mitigation measures in earthquake affected areas, Engineer-in-Chief's Branch, Pakistan Army, A power point presentation delivered to Military College of Engineering, National University of Sciences and Technology, Risalpur, Pakistan, 2006.

[13] Google Map, "Satellite imagery," 2020, https://www.google .com/maps.

[14] T. Kiyota, A. Sattar, K. Konagai, Z. A. Kazmi, D. Okuno, and T. Ikeda, "Breaching failure of a huge landslide dam formed by the 2005 Kashmir earthquake," Soils and Foundations, vol. 51, no. 6, pp. 1179-1190, 2011.

[15] A. Sattar, K. Konagai, T. Ikeda, T. Kiyota, Z. A. Kazmi, M. Koikes et al., "A quantitative approach to assess landform changes of Hattian Ballah landslide dam formed by the 2005 Kashmir Earthquake," Bulletin of Earthquake Resistant Structure Research Center, no. 42, pp. 19-20, 2009.

[16] M. Basharat, J. Rohn, and M. R. Khan, "Effect of drawdown of Karli lake: a case study of Karli landslide hazard in District Hattian, Northeast Himalayas of Pakistan," Life Science Journal, vol. 11, no. 9, pp. 610-616, 2014.
[17] J. F. Schneider, F. E. Gruber, and M. Mergili, "Recent cases and geomorphic evidence of landslide-dammed lakes and related hazards in the mountains of Central Asia," in Landslide Science and Practice, C. Margottini, P. Canuti, and K. Sassa, Eds., pp. 57-64, Springer, Berlin, Heidelberg, 2013.

[18] Google Earth Timelapse, "Zalzal lake $34^{\circ} 09^{\prime} 17^{\prime N}, 73^{\circ} 42^{\prime} 11^{\prime E}$, Camera: 9250 m," 2020, https://earthengine.google.com/ timelapse/.

[19] ASTM D6431-18, Standard guide for using the direct current resistivity method for subsurface investigation, ASTM International, West Conshohocken, PA, 2018.

[20] M. H. Loke, Tutorial: 2-D and 3-D electrical imaging surveyCourse notes, Geotomo software, Penang, MalaysiaJuly 2020, https://www.geotomosoft.com/downloads.php.

[21] ASTM D6913/D6913M-17, Standard test methods for particlesize distribution (gradation) of soils using sieve analysis, ASTM International, West Conshohocken, PA, 2017.

[22] ASTM D1140-17, Standard test methods for determining the amount of material finer than 75- $\mu m$ (no. 200) sieve in soils by washing, ASTM International, West Conshohocken, PA, 2017.

[23] ASTM D4318-17, Standard test methods for liquid limit, plastic limit, and plasticity index of soils, ASTM International, West Conshohocken, PA, 2017.

[24] ASTM D2487-17e1, Standard practice for classification of soils for engineering purposes (unified soil classification system), ASTM International, West Conshohocken, PA, 2017.

[25] ASTM D5856-15, Standard test method for measurement of hydraulic conductivity of porous material using a rigid-wall, compaction-mold permeameter, ASTM International, West Conshohocken, PA, 2015.

[26] ASTM G57-06, Standard test method for field measurement of soil resistivity using the Wenner four-electrode method, ASTM International, West Conshohocken, PA, 2012.

[27] R. Fell, C. F. Wan, J. Cyganiewicz, and M. Foster, “Time for development of internal erosion and piping in embankment dams," Journal of Geotechnical and Geoenvironmental Engineering, vol. 129, no. 4, pp. 307-314, 2003.

[28] W. Meyer, R. L. Schuster, and M. A. Sabol, "Potential for seepage erosion of landslide dam," Journal of Geotechnical Engineering, vol. 120, no. 7, pp. 1211-1229, 1994.

[29] J. L. Sherard, "Sinkholes in dams of coarse, broadly graded soils," in Transactions, 13th International Congress on Large Dams (ICOLD), vol. 2, pp. 25-35, New Delhi, India, 1979.

[30] A. Kézdi, Soil Physics, vol. 25, Elsevier Scientific Publishing Company, Amsterdam; Oxford, New York, 1979.

[31] Climate Data Oline, Precipitation data: Islamabad, PK (CITY:PK000003) 1980-01-01 to 2018-12-31National Centers for Environmental Information, National Oceanic and Atmospheric Administration (NOAA)July 2020, https://www.ncdc .noaa.gov/cdo-web/datasets/.

[32] ASTM D3977-97 (Re-approved 2019), Standard test methods for determining sediment concentration in water samples, ASTM International, West Conshohocken, PA, 2012.

[33] V. F. De Mello, "Some lessons from unsuspected, real and fictitious problems in earth dam engineering in brazil," in Proceedings of the 6th Regional Conference for Africa on Soil Mechanics and Foundation Engineering, Durban, South Africa, 1975.

[34] R. B. Peck, "Advantages and limitations of the observational methods in applied soil mechanics," in Géotechnique, vol. 19 of Ninth Rankine Lecture, no. 2, 1969. 